\title{
THE STRUCTURAL CHEMISTRY OF IIA GROUP METAL DIKETONATES
}

\author{
Andrei Drozdov and Sergei Troyanov* \\ Moscow State University, Department of Chemistry, 119899 Moscow, Vorobjevy Gory, Russia
}

The structural chemistry of the IIA group metal diketonates $(\mathrm{M}=\mathrm{Mg}, \mathrm{Ca}, \mathrm{Sr}, \mathrm{Ba})$ is reviewed. A special attention is given to Ba compounds as the most challenging in MOCVD of HTSC thin films. The structures are described according to the structural principles: nuclearity, types of ligands and the coordination modes. Some correlations between the crystal structure, volatility and storage stability are discussed.

CONTENT

Introduction

1. Methods of synthesis

2. Structural Chemistry of group 2 metal diketonates

2.1. General consideration

2.1.1. Coordination numbers of the metal

2.1.2. Coordination modes of the ligand

2.2. Review of the crystal structures

2.2.1. Homoligand metal diketonates and close related complexes

2.2.2. Mixed ligand complexes

2.2.2.1. Anionic additional ligand

2.2.2.2. Neutral Lewis base

2.3. Mixed metal diketonates

2.4. Anionic metal diketonates

2.5. Some correlations in the structural chemistry

3. Structure depending properties

\section{ABBREVIATIONS}

azatetraglyme - 8-aza-2,5,11,14-tetraoxapentadecane

$\mathrm{CN}$ - coordination number

diglyme - 2,5,8-trioxanonane

dipy - 2,2'-dipyridyl

DMF - dimethylformamide

Hacac - pentane-2,4-dione (acetylacetone)

Hdbzm - 1,3-diphenylpropane-1,3-dione (dibenzoylmethane)

Hdiki - 2,2-dimethyl-N-(3,6-dioxaheptyl)hexane-3-one-5-imine

Hdmmod - 2,2-dimethyl-8-methoxyoctane-3,5-dione

Hhfa - 1, 1, 1,5,5,5-hexafluoropentane-2,4-dione

Hhfhd - 1,1,1,2,2,3,3-heptafluoro-6-perfluorocyclohexylhexane-4,6-dione

HL - $\beta$-diketone

hmteta - 2,5,8,11-tetramethyl-2,5,8,11-tetraazadodecane

Hmthd - 2,2,6-trimethyl-6-methoxyheptane-3,5-dione

Hpiv - 2,2,2-trimethylacetic acid

Hpta - 1,1,1-trifluoro-5,5-dimethylhexane-2,4-dione 
Htdfnd - 1,1,1,2,2,3,3,7,7,8,8,8,9,9-tetradecafluorononane-4,6-dione

Htfa - 1,1,1-trifluoropentane-2,4-dione

Hthd - 2,2,6,6-tetramethylheptane-3,5-dione (dipivaloylmethane)

Htriki - 2,2-dimethyl-N-(3,6,9-trioxaundecyl)hexane-3-one-5-imine

HTSC - high temperature superconductor

mbhexaglyme - 2,5,8,1 1,14,17,20-heptaoxatetracosane (methylbutyl-hexaglyme)

mep - 2,5,8,11,14,1-hexaoxanonadecane (methylethylpentaglyme)

MOCVD - metal organic chemical vapour deposition

phen - 1,10-phenanthroline

tetraglyme - 2,5,8,11,14-pentaoxapentadecane

tmnd - 1,8-bis-(dimethylamino)naphthalene

triglyme -2,5,8,11-tetraoxadodecane

INTRODUCTION

The discovery of high-temperature superconductivity by Bednorz and Muller in 1986 [1] has initiated intensive research in the synthesis and properties of yttrium, barium, bismuth , thallium and copper diketonates. One important method of producing HTSC thin films is MOCVD and the best precursors are diketonate metal complexes [2-4]. One difficulty in making superconducting films with diketonate precursors is that the barium chelates are less volatile and thermally stable than the copper and lanthanide precursors. This has lead to renewed interest in studying the stability, composition and thermal properties of alkaline-earth diketonates. Therefore, a number of publications in this field increased greatly.

The most suitable in MOCVD are metal complexes with dipivaloylmethane, which contains the bulky tert-Bu groups providing weak intermolecular interactions and therefore rather high volatile chelates. Although the first crystal structures were known since 1960 th's $[5,6]$ the pioneer works were really made by Sievers [7] and Gleizes [8], who determined the X-ray structures of barium dipivaloylmethanate derivatives which are of vital importance for MOCVD of HTSC films.

A progressive accumulation of the data on crystal structures combined with the investigation of thermal properties permits to understand the main principles important for the prediction of volatility of the new compounds, the stability in storage, the choice of the synthetic technique. This review is devoted to the fundamental problems of the structural chemistry of IIA group metal diketonates $(\mathrm{Mg}, \mathrm{Ca}, \mathrm{Sr}, \mathrm{Ba})$, the synthetic part being briefly outlined. All the compounds containing $\mathrm{Mg}, \mathrm{Ca}, \mathrm{Sr}, \mathrm{Ba}$ and one or more diketonate group are discussed herein. Because Be occupies a special position in the IIA group and has special properties different from those of $\mathrm{Mg}$ and alkaline-earth elements, it has not been included in this paper. Efforts were made to include all the crystal data known and in some cases those which has not been published yet.

\section{METHODS OF SYNTHESIS}

IIa Group metal diketonates are the white crystalline solids soluble in ether, alcohol, DMF or in the mixtures of these solvents, and as a rule insoluble in water. Some of them can be sublimed in vacuo.

The synthesis of magnesium and alkaline-earth metal diketonates generally does not present special difficulties and as a rule gives good yields. All the synthetic methods used can be divided into three main groups: the exchange reactions, the oxidation-reduction processes and the thermal decomposition of mixed ligand diketonates. The former reactions are performed between the pure diketone or its conjugated base and a IIA group metal compound such as a salt $[9,10]$, an alkoxide [11-13] or hydroxide [7]. If the medium becomes acidic during the reaction, it is necessary to add some alkali or ammonia to shift the equilibrium as done by Caulton [14]. When using a donor 
solvent (e.g. water, ether, alcohol) as the reaction medium the interaction often gives solvates with donor solvent molecules coordinated to the metal ion [7, 9, 11, 15-17]. In order to select the reagents one should take into account that in some cases the composition of the final product strictly depends on the synthetic method used. A typical example is the synthesis of hydrated barium dipivaloylmethanate. It was found in [7] that the product of the reaction between $\mathrm{Ba}(\mathrm{OH})_{2}$ and $\mathrm{Hthd}$ is $\mathrm{Ba}_{5}(\text { thd })_{9}(\mathrm{OH})\left(\mathrm{H}_{2} \mathrm{O}\right)_{3}$, while the interaction between $\mathrm{Ba}\left(\mathrm{NO}_{3}\right)_{2}$ and $\mathrm{Na}$ (thd) produces $\left[\mathrm{Ba}_{6}(\text { thd })_{12}\left(\mathrm{H}_{2} \mathrm{O}\right)_{13}\right]$ [9]. Using $\mathrm{BaCl}_{2}$ and sodium thd-derivative as the reagents $\mathrm{Ba}_{5}(\text { thd })_{9} \mathrm{Cl}\left(\mathrm{H}_{2} \mathrm{O}\right)_{7}$ could be isolated after storage of the precipitate under the mother solution containing $\mathrm{Cl}^{-}$ions [10].

The second route to synthesize alkaline-metal diketonates is the oxidation-reduction reaction between a metal [18-20] (or its amide, hydride [21]) and a diketone in the absence of water or other donor solvent.

The third type of reactions that can be used is the thermal decomposition of mixed ligand complexes with weakly coordinated neutral Lewis bases such as water, ammonia, ether or alcohol. This method is convenient for obtaining volatile metal diketonates as the substance can be additionally purified by vacuum sublimation [11, 22-24].

The complex synthesized in solution differs from that obtained by the thermal decomposition followed by sublimation. For instance, two crystal modifications of the complexes are known differing only by the molecular packing for $\mathrm{Ba}_{4}(\text { thd })_{8}[8,18]$, while the structure of molecules is different in two forms of $\mathrm{Ba}(\mathrm{hfa})_{2}(18-\mathrm{C}-6)[25,26]$ (vide infra). In the case of the mixed ligand compound $\mathrm{Ba}_{6}(\text { thd })_{10}\left(\mathrm{O}_{2}\right)\left(\mathrm{H}_{2} \mathrm{O}\right)_{3}$ the use of different reagents in the exchange method resulted in the formation of somewhat different crystal products that can occasionally contain solvent molecules [27-29]. With the fluorinated diketonates water-containing media should be avoided. Otherwise, a fluorinated tetraol could be obtained as a by-product [30]. To prepare mixed ligand complexes an ion exchange or a redox reaction can be used taking a mixture of diketone and the additional ligand in the suitable proportions instead of pure diketone or its conjugated base $[31,32]$.

In some cases, it is necessary to work in the inert atmosphere as the by-reactions with carbone dioxide or moisture are possible [27,33]. Pure homoligand metal diketonates are stable in evacuated ampoules. On the contrary, the hydrated compounds change when stored loosing their volatility because of hydrolysis. Keeping the compounds of both types under air causes carbonate formation and hydrolysis [34, 35].

\section{STRUCTURAL CHEMISTRY OF GROUP 2 METAL DIKETONATES}

\subsection{GENERAL CONSIDERATION}

\subsubsection{Coordination numbers of the metal}

In accordance with the increase of the atom and ion radii in the row $\mathrm{Mg}-\mathrm{Ca}-\mathrm{Sr}-\mathrm{Ba}$ the $\mathrm{CN}$ 's range from minimum 6 to maximum 11: for $\mathrm{Mg}$ the only $\mathrm{CN}$ known is 6 , for $\mathrm{Ca}$ and $\mathrm{Sr}$ - from 6 to 9 , for $\mathrm{Ba}$-from 6 to 11. Magnesium and calcium possess as a rule $\mathrm{CN}=6$ in their diketonates, but some examples with $\mathrm{CN}(\mathrm{Ca})=8$ are also known $[32,36,37]$. For strontium $\mathrm{CN}=9$ [38] appears to be the highest possible. For barium $\mathrm{CN}=7-9$ are the most common. The lower $\mathrm{CN}$ (six) occurs due to the steric hindrance only in the complexes with bulky ligands [18].

As in the mononuclear IIA metal diketonate with a formula $\mathrm{ML}_{2}$ the covalency of the central ion would be four (that is not sufficient to complete the coordination sphere even in the case of the smallest $\mathrm{Mg}$ ) these compounds have a great tendency to form oligomeric structures with the bridging oxygen atoms. Many oligomeric molecules have been found even in the gas phase at elevated temperature [7, 39-40]. The introduction of the additional donors located either in some other molecules or in the same diketonate ion allows to vary the oligomerization degree over a wide range (from mononuclear compounds to polymers). In both cases the CN of IIA group 
metal increases. If the ligand contains some other functional groups with donor atoms (besides two carbonyl groups) some additional M-L bonds are formed [22]. A substituted dipivaloylmethanate, which contains one methoxy group taking part in the coordination to the metal ion can be an example. For the fluorinated diketonates the additional weak interactions between the metal and fluorine atoms from trifluoromethyl or difluoromethylene groups are typical [41-43].

\subsubsection{Coordination modes of the ligand}

In all magnesium and alkaline-earth diketonates studied the ligand is linked with the metal by the oxygen atoms of the diketonate with the formation of a six-member chelate ring with the central atom. The only exception known is the structure of $\left[\mathrm{enH}_{2}\right]_{1.5}\left[\mathrm{Ba}(\mathrm{hfa})_{5}\right]$, in which one diketonate ligand is monodentate [44]. Depending on the number of $M-O(L)$ bonds and the number of the chelate rings formed the diketonate ligands can be divided into several types (coordination modes) (Fig. 1). This classification is based on the treatment of the ligand as a whole (we account the whole number of chelate rings and the whole number of $\mathrm{M}-\mathrm{O}$ bonds) if compared with some other works where every donor atom of the ligand is accounted separately. In the simplest
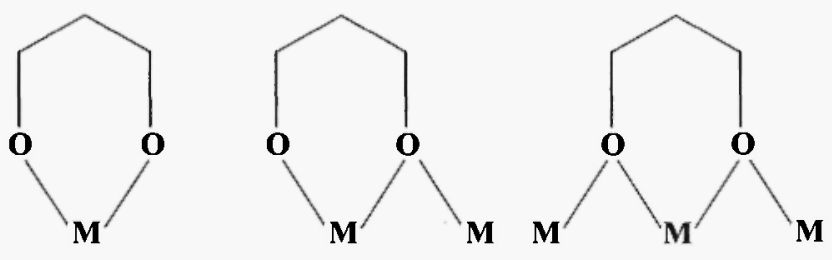

1a

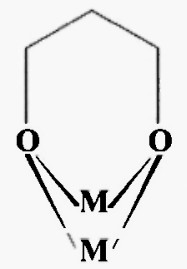

$2 a$
$1 \mathrm{~b}$

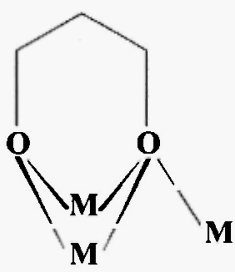

$2 b$

case the monoanion of the diketone is monochelating: it is bidentate, forming one chelate ring (type 1a) and only two $\mathrm{M}-\mathrm{O}$ bonds. This coordination mode is typical for the mixed ligand complexes in which the metal atom is sterically hindered and high CN's are achieved due to the coordination of the additional ligands. This coordination mode occurs more scarcely in the homoligand diketonates with the low CN's of the metal. Thus, in $\mathrm{Ba}_{4}$ (thd $)_{8}$ only two of the eight thd ligands belong to the type 1a [18]. The tendency of alkaline-earth metals to possess high CN's results in the oligomerization through the formation of $\mathrm{M}-\mathrm{O}-\mathrm{M}$ bridges (if there are no other donors in the system). We treat these coordination modes as monochelating

bridging (1b), monochelating double bridging (1c) and so on. Only one example of monochelating triple bridging ligand (1d) is known [42, 43].

In some $\mathrm{Sr}$ and $\mathrm{Ba}$ diketonates the other type of coordination takes place (2a). It is found till now only in complexes with the thd ligand, which can be possibly explained by the fact that many more the number of thd complexes have been studied as compared to other diketonate complexes. In this coordination mode both $\mathrm{O}$ atoms of diketonate are bidentate bridging, linking two barium atoms. In other words, the thd anion simultaneously takes part in the formation of two six member chelate rings with two metal atoms. Then, both chelate rings are bent, the - $\mathrm{CO}-\mathrm{CH}-\mathrm{CO}$ - group of the thd-ligand being situated in a plane which is perpendicular to the $\mathrm{Ba}$...Ba line. A double chelating bridging diketonate, which forms a fifth $\mathrm{Ba}-\mathrm{O}$ bond in addition to two chelate rings (2b) has been also found. 
The last two coordination modes (2a and $\mathbf{2 b}$ ) are known nowadays only for IIA metal diketonates. A wide variety of different coordination modes found in the alkaline-earth metal diketonates as well as the strong deviations from the planarity and the differences in the M-O distances even in the ligands of type 1a can be explained only by the great ionicity of the M-O bond in the IA-IIIA group metal complexes and by the large CN's of metal.

\subsection{REVIEW OF THE CRYSTAL STRUCTURES}

For the sake of convenience the crystal structures are presented in the following order: first the structures of the homoligand IIA metal diketonates, then those of the mixed ligand (with anionic and neutral additional ligands), and finally those of the anionic diketonates. A borderline case when a donor solvent acting as a weak Lewis base does not alter greatly the structure if compare with homoligand species is presented before the heteroligand complexes but after the homoligand ones.

All the data discussed are presented in the Tables I-IV in accordance with their nuclearity and the main structural features. The column "formula" reflects the composition and partially the structure of the complex, the CN's are given for every crystallographically independent metal atom. In the next column $\mathrm{Ba}-\mathrm{O}$ distances are presented separately for each type of ligand coordination corresponding to Fig. 1. Index " $b$ " shows the bridging function of the ligand, all other bonds belong to the chelate rings. For the mixed ligand complexes $\mathrm{Ba}-\mathrm{O}(\mathrm{Q})$ distances are given separately.

The figures are chosen in a way to present the structures which are not easily accessible for a reader. The figures were drawn using the data of the Cambridge Structural Data Base [45a].

\subsubsection{Homoligand metal diketonates and close related complexes}

The examples of the X-Ray structures of the IIA metal complexes which contain diketonate as an only ligand have been studied only recently. This fact is connected with the low solubility of the majority of such compounds in non-donor solvents such as pentane or hexane. The recrystallization even from weak donor solvents often results in the formation of mixed ligand complexes with solvent molecules coordinated to the metal $[11,15]$. The other possible approach to the synthesis of homoligand diketonates is the vapor crystallization, but it can be used only in the case of the volatile chelates.

As far as we know, there are no structural data for the homo-ligand $\mathrm{Mg}$ and $\mathrm{Ca}$ diketonates until now. The only $\mathrm{Sr}$ complex studied is $\mathrm{Sr}_{3}(\text { thd })_{6}(\mathrm{Hthd}) \mathrm{C}_{6} \mathrm{H}_{5} \mathrm{Me} \mathrm{C}_{5} \mathrm{H}_{12}$ [12], though it contains besides the thd-ion a neutral Hthd ligand and additional solvent molecules. This structure consists of the trinuclear molecules with the $\mathrm{Sr}$ atoms forming a triangle with the $\mathrm{Sr}$...Sr distances varying from 3.63 to $4.11 \AA$. Each $\mathrm{Sr}$ atom is chelated by one thd-ligand of type $1 \mathrm{a}$. In accordance with the values of $\mathrm{C}-\mathrm{C}$ bonds one of these ligands containing atoms $\mathrm{O}(11)$ and $\mathrm{O}(12)$ (Fig. 2) is protonated that can be confirmed by a swivel of the chelate ring around $\mathrm{C}-\mathrm{C}$ bond $\left(39^{\circ}\right)$ as can be seen from Fig. 2b. Thd ligands with coordination modes $\mathbf{1 b}, \mathbf{1 c}, \mathbf{2 b}$ link the metal atoms in a molecule (for the ranges of Sr-O distances see Table I). The CN's of Sr atoms in this structure vary from 6 to 7 and even 8 . This chelate seems to preserve trinuclearity due to the coordination of Hthd only.

According to the mass-spectroscopy data trinuclear species are also found in the vapor of $\mathrm{Ba}$ dipivaloylmethanate [39]. Moreover, the structure of $\mathrm{Ba}_{3}(\mathrm{thd})_{6}$ in the solid state has been proposed in $[46,47]$, but without any supporting experimental data. In the structure proposed all three Ba atoms are linked by the thd-ligands of type $2 \mathrm{a}$ and in addition every $\mathrm{Ba}$ atom is chelated by one $1 \mathrm{a}$ thd ion. Accordingly all $\mathrm{Ba}$ atoms are six coordinated, that is not typical. Moreover, the crystalline structures of two different modifications of this compound are known: one derived from solution (modification a) [12, 18], another from vapor phase (modification b) [8, 24], of which the former 


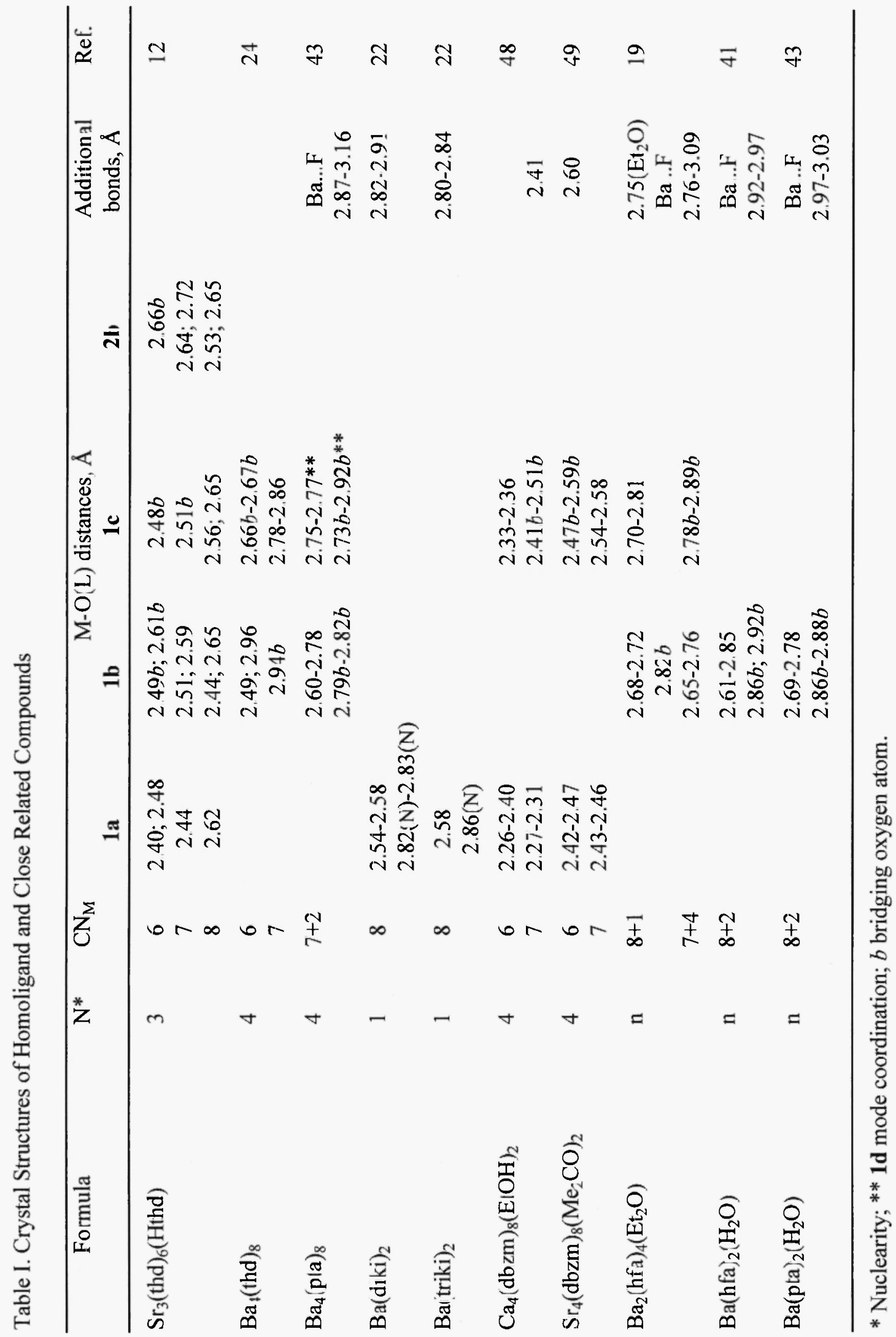




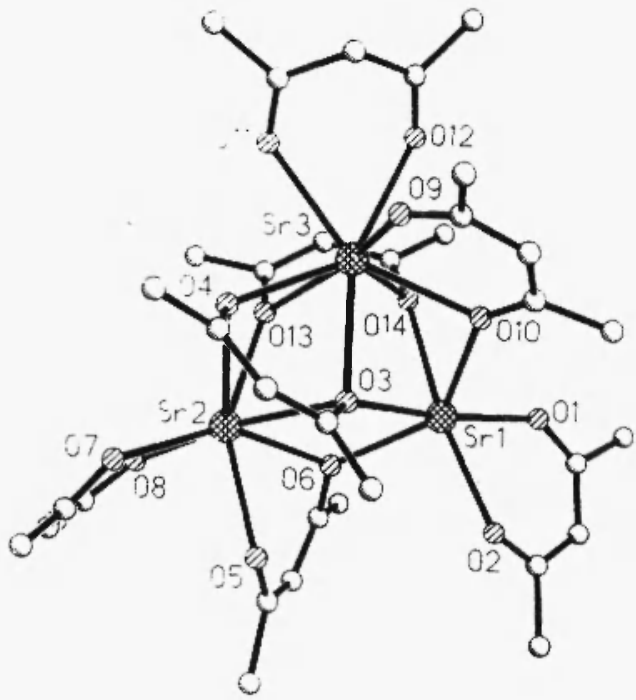

a

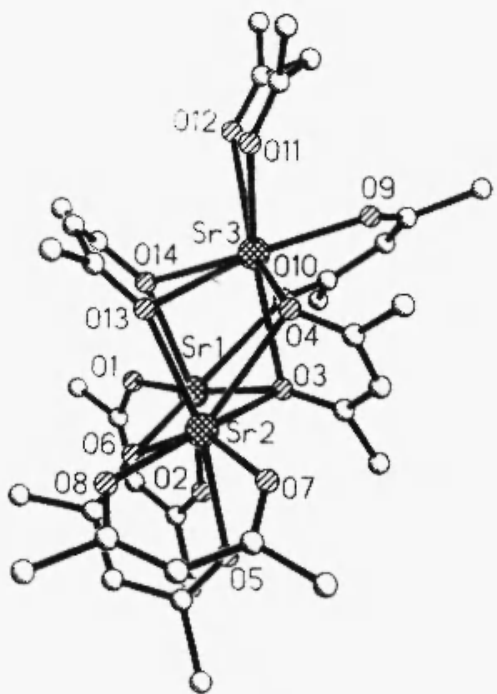

b

Fig. 2. Trinuclear unit in the structure of $\mathrm{Sr}_{3}(\text { thd })_{6}(\mathrm{Hthd}) \cdot \mathrm{C}_{6} \mathrm{H}_{5} \mathrm{Me} \cdot \mathrm{C}_{5} \mathrm{H}_{12}$.

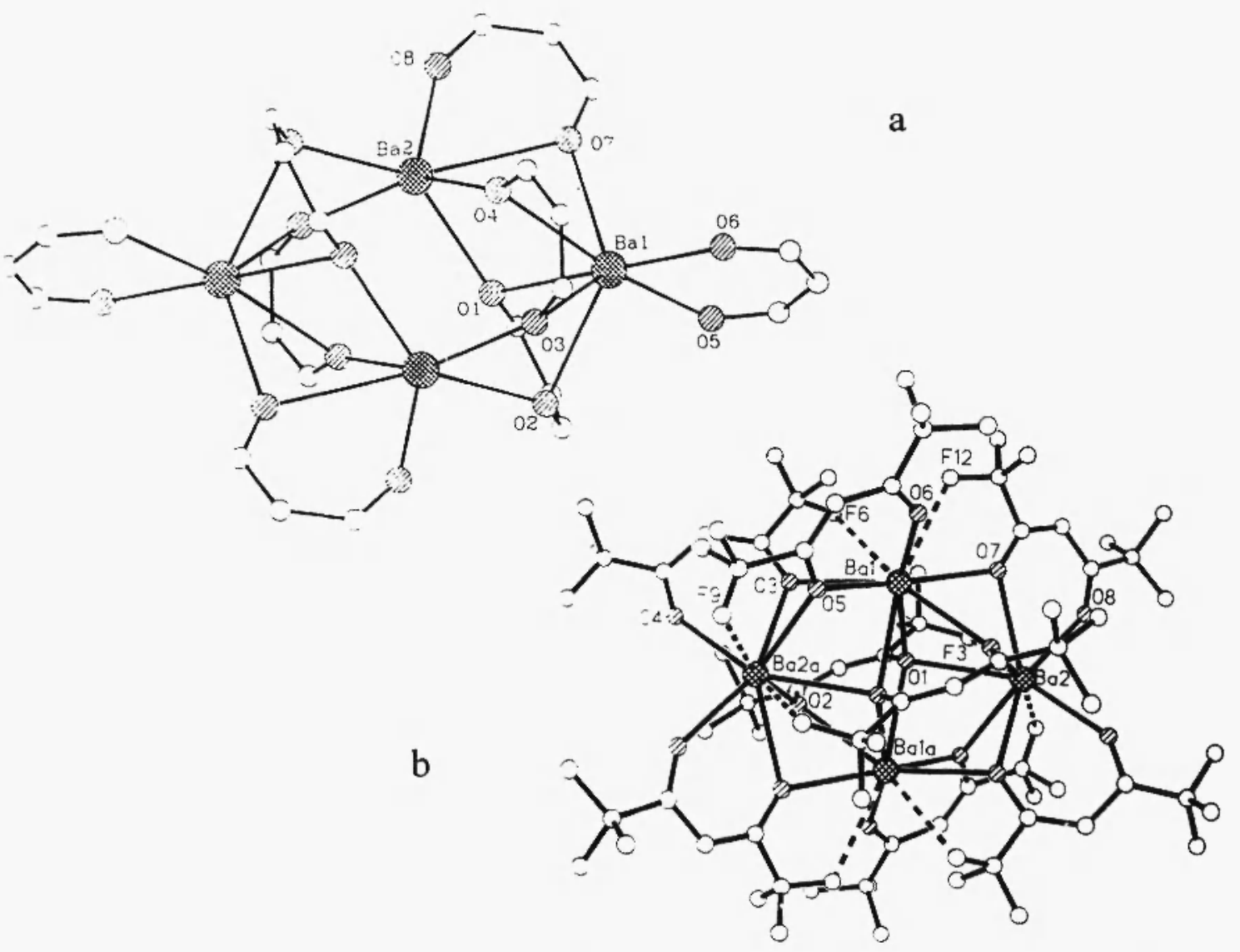

Fig. 3. The molecular structure of $\mathrm{Ba}_{4}(\text { thd })_{8}$ (tert-Bu groups are omitted) (a) and $\mathrm{Ba}_{4}(\mathrm{pta})_{8}(\mathrm{~b})$. 
seems to be more stable as having a higher density. Both modifications consist of virtually the

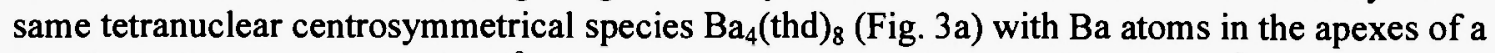
rhombus with an angle nearly $60^{\circ}$. Ba... Ba distances range from 4.142 to $4.205 \AA$, the $\mathrm{CN}$ 's of $\mathrm{Ba}$ atoms are 6 and 7. Two thd ligands in a molecule of the complex belong to type 1a, two to $1 \mathbf{b}$ and four to $1 \mathrm{c}$ (if the distance $\mathrm{Ba}(2)-\mathrm{O}(2) 3.28 \AA$ is not considered as a bond). The two modifications differ one from another only by the packing mode of the tetranuclear molecules: the modification (a) is triclinic, while (b) is orthorhombic. The structural investigation of (a)- $\mathrm{Ba}_{4}(\text { thd })_{8}$ at $150 \mathrm{~K}$ [12] showed that at this temperature one of the $O$ atoms is shifted slightly by $0.14 \AA$, that can be interpreted as the alteration of the coordination mode of two ligands (two $\mathbf{1 b}$ ligands became $\mathbf{2 b}$ ). These changes are also responsible for small $(0.02 \AA)$ increase of $\mathrm{Ba}$...Ba distance due to the shift of some thd-ligands. The $\mathrm{CN}$ of all $\mathrm{Ba}$ atoms in this case becomes 7 .

Sublimed $\mathrm{Ba}_{4}(\mathrm{pta})_{8}$ is a centrosymmetric tetramer $[42,43]$ with $\mathrm{Ba}$ atoms forming rhombus (Fig. 3b) (Ba...Ba $4.07-4.20 \AA$ for both crystallographically independent molecules). If $\mathrm{Ba}$...F contacts are not taken into account, six pta ligands can be considered as $1 \mathbf{b}$, while the other two $(\mathrm{O}(1) ; \mathrm{O}(2))$ are of type 1d, which is unique for all the structures known till now. Due to the weak bonding between $\mathrm{Ba}$ and $\mathrm{F}$ atoms of the trifluoromethyl groups of the ligand (Ba...F 2.87 - 3.29 $\AA$ ) the $\mathrm{CN}$ of all four $\mathrm{Ba}$ atoms is nine.

The other homoligand complexes are mononuclear ketoiminates $\mathrm{Ba}(\mathrm{diki})_{2}$ and $\mathrm{Ba}(\text { triki })_{2}$ [22], where the ligands contain some ether groups in addition to the ketoiminate fragment. The $\mathrm{CN}$ in both compounds is eight. In $\mathrm{Ba}(\mathrm{diki})_{2}$ (Fig. 4) the central atom is chelated by all the donor atoms ( 30 and $\mathrm{N}$ ), while in the similar complex with triki the oxygen atom of the terminal ethoxy group is non coordinated. The crystal structure of the relative barium complex with the polyether spanning two ketoiminate ligands with tert-Bu groups into one ligand with eight donor atoms (4 ether oxygen atoms, 2 ketoiminate oxygen and 2 ketoiminate nitrogen atoms) shows the compound to be coordinately saturated [45b,45c]. According to the supposition made in [46] the compound $\mathrm{Ba}(\mathrm{dmmod})_{2}$ is mononuclear due to the additional coordination of the methoxy group, although in this instance the $\mathrm{CN}$ of $\mathrm{Ba}$ is six in contrast to those in ketoiminates.

Very close to the monoligand

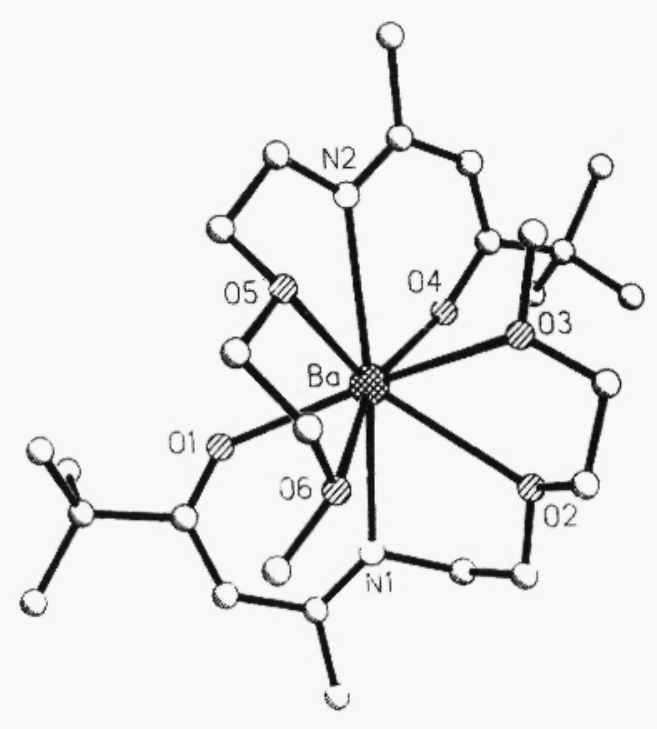

Fig. 4. The molecular structure of $\mathrm{Ba}(\text { diki })_{2}$ chelates discussed above are the IIA group metal complexes which contain, in addition to the chelated diketonate ions, the coordinated molecules of a solvent. These compounds were obtained in attempting to isolate a homoligand diketonate from the donor solvent and in our opinion retain the nuclearity of the initial homoligand complexes. Thus, the crystal structure of the compound isolated by the recrystallization of calcium dibenzoylmethanate from ethanol consists of the tetranuclear centrosymmetric molecules $\mathrm{Ca}_{4}(\mathrm{dbzm})_{8}(\mathrm{EtOH})_{2}$ [48]. Four $\mathrm{Ca}$ atoms which form a rhombus are linked by four monochelating double bridging dbzm-ligands (type 1c). The other four dbzm ions form chelate rings with every metal atom (type 1a). One crystallographically independent $\mathrm{Ca}$ atom is hexacoordinated, another has $\mathrm{CN}=7$ due to the 
coordination of the solvent. The average $\mathrm{Ca}-\mathrm{O}(\mathrm{dbzm})$ distance is $2.37 \AA$, that is close to a sum of ionic radii of $\mathrm{Ca}$ and $\mathrm{O}(2.39 \AA)$. Two of four structurally independent chelate rings are non planar. The other tetranuclear complex with the similar structure is $\mathrm{Sr}_{4}(\mathrm{dbzm})_{8}\left(\mathrm{Me}_{2} \mathrm{CO}\right)_{4}$ [49]. It has been synthesized in much the same way but from another solvent (acetone).

In the structure of $\left[\mathrm{Ba}_{2}(\mathrm{hfa})_{4}\left(\mathrm{Et}_{2} \mathrm{O}\right)\right]_{\mathrm{n}} \mathrm{Ba}$ atoms form infinite zigzag chains [19] (Fig. 5a). Each three adjacent $\mathrm{Ba}$ atoms are linked by two hfa-ligands of $1 \mathrm{c}$ type, every oxygen atom being $\mu$-bidentate. The other two hfa ions belong to the $\mathbf{1 b}$ coordination mode. The ether molecule in the structure is monodentate and is coordinated only to one of two $\mathrm{Ba}$ atoms. The $\mathrm{Ba}$...F interactions found in this structure (Ba...F $2.76-3.09 \AA$ ) increase the $\mathrm{CN}$ of metal atoms up to 9 and 11 (not taking into account the $\mathrm{Ba}$...F contacts $\mathrm{CN}$ 's are 8 and 7 respectively).

a
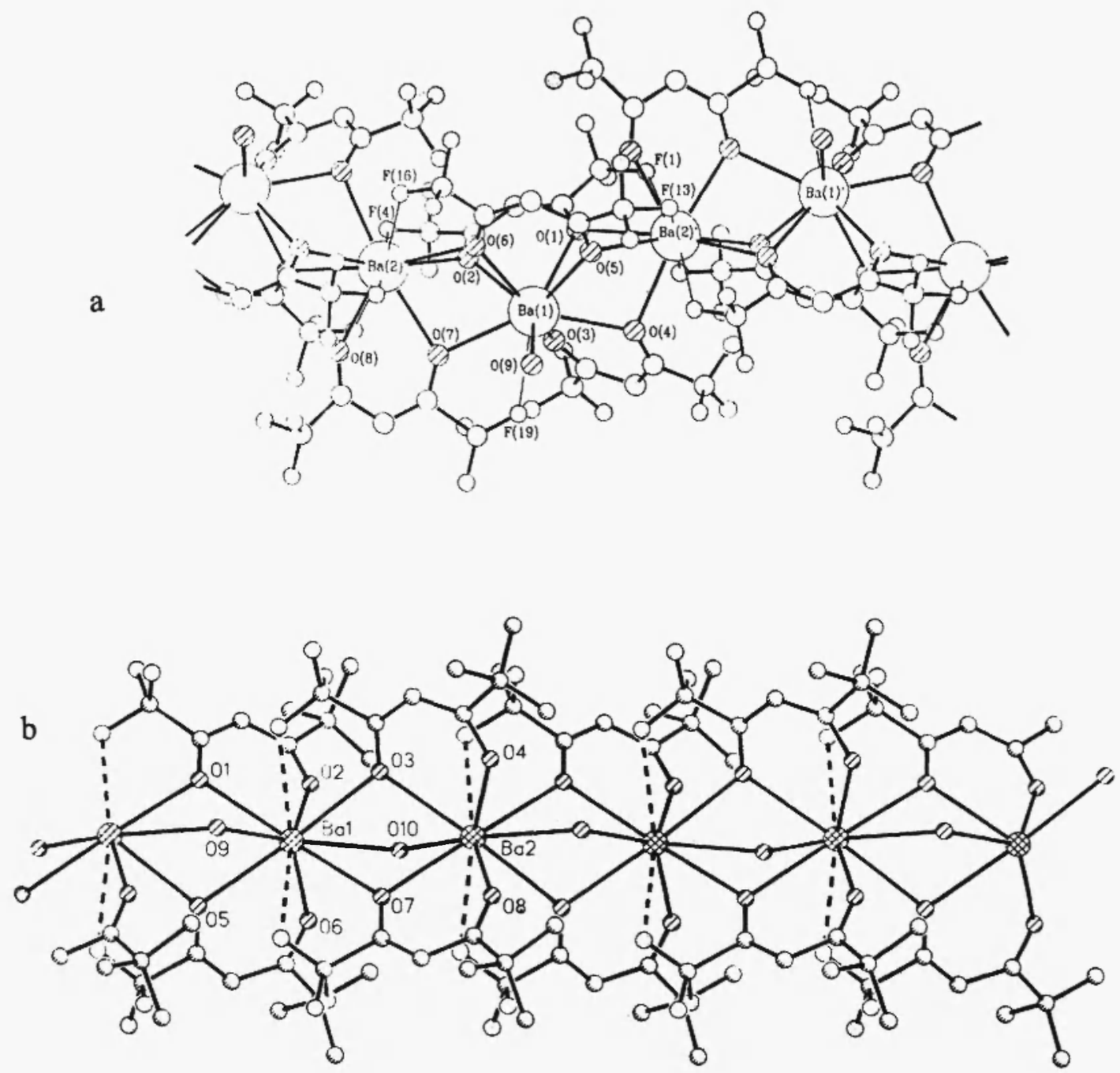

Fig. 5 Polymer chains in the crystal structure of $\mathrm{Ba}(\mathrm{hfa})_{2} \cdot \mathrm{Et}_{2} \mathrm{O}$ (a) and $\mathrm{Ba}(\mathrm{pta})_{2} \cdot \mathrm{H}_{2} \mathrm{O}$ (b).

The hydrates $\left[\mathrm{BaL}_{2}\left(\mathrm{H}_{2} \mathrm{O}\right)\right]_{\mathrm{n}},(\mathrm{L}=\mathrm{hfa}[41]$, pta $[42,43])$ are both structurally close to the complex with ether. They are also chain polymers with $\mathrm{Ba}$ atoms coordinated by diketonate ligands of the type $1 \mathrm{~b}$ and by the $\mu-\mathrm{H}_{2} \mathrm{O}$ molecules $(\mathrm{O}(9)$ and $\mathrm{O}(10)$, Fig. 5b). In both structures the central atoms are ten coordinated including $\mathrm{Ba} . . . \mathrm{F}$ interactions. 


\subsubsection{Mixed ligand complexes}

These substances can be divided into two separate groups:

1) complexes containing besides the diketonate ions one or more negatively charged ligands $\left(\mathrm{Cl}^{-}\right.$, $\mathrm{OH}^{-}$etc);

2) complexes diketonates with neutral additional Lewis bases $\left(\mathrm{H}_{2} \mathrm{O}, \mathrm{CH}_{3} \mathrm{OH}, \mathrm{NH}_{3}\right.$, dipy and others).

\subsubsection{Anionic additional ligands}

The examination of the crystal structures of mixed ligand IIA -metal diketonates containing small anionic ligands $\left(\mathrm{Cl}^{-}, \mathrm{OH}^{-}\right.$, piv $\left.{ }^{-}\right)$reveals an increase of the nuclearity with respect to such homoligand compounds as tetranuclear $\mathrm{Ba}_{4}(\text { thd })_{8}$ and $\mathrm{Ba}_{4}(\mathrm{pta})_{8}$ (Table II). Among the compounds of this group pentanuclear $[10,18,44]$, hexanuclear $[10,27-29,46]$ and polymeric $[10,31]$ complexes are known. Up to date, the $\mathrm{X}$-Ray structures of three pentanuclear compounds with a composition $\mathrm{Ba}_{5}$ (thd $)_{9} \mathrm{XZ}_{\mathrm{y}}$ where $\mathrm{X}=\mathrm{Cl}\left(\mathrm{Z}=\mathrm{H}_{2} \mathrm{O}, \mathrm{y}=7\right)$ [10], $\mathrm{X}=\mathrm{OH}\left(\mathrm{Z}=\mathrm{H}_{2} \mathrm{O}, \mathrm{y}=3\right)$ [44], $\mathrm{X}=\mathrm{piv}$ $(y=0)[18]$ have been published. The complexes with chloride and hydroxy groups consist of pentanuclear molecules with a square pyramidal arrangement of $\mathrm{Ba}$ atoms (Fig. 6). Every $\mathrm{Ba}$ is coordinated by one 1a thd-ligand, the other thd anions being of types $\mathbf{1 b}$ and $\mathbf{1 c}$. All water molecules are bridging. The main distinction between these two structures is that the Cl-atom is situated at approximately the same distances from all five Ba atoms, while the hydroxy group is closer to one $\mathrm{Ba}$ than to the others.

The arrangement of $\mathrm{Ba}$ atoms in the pentanuclear mixed ligand pivalatedipivaloylmethanate $\mathrm{Ba}_{5}$ (thd) (piv) $_{9}$ [18] resembles an open envelope. This shape of metal frame can be derived from a square pyramid shifting the apical $\mathrm{Ba}$ atom in the plane parallel to the base. This kind of framework seems to be caused by steric hindrance that do not occur in the case of $\mathrm{Cl}$ and $\mathrm{OH}$, but have to take place in the case of piv. Actually, the pivalate ion has a greater size with two donor atoms situated at the rather long distances so that both are able to coordinate all five $\mathrm{Ba}$ atoms.

Using the polydimethylsiloxane anion, that is much larger than piv, a hexanuclear compound $\mathrm{Ba}_{6}(\text { thd })_{10}\left(\mathrm{Me}_{2} \mathrm{SiO}_{2}\right) \cdot \mathrm{H}_{2} \mathrm{O}$ [46] was obtained. In this complex the $\mathrm{Ba}$ atoms have a boat conformation, every $\mathrm{O}$ atom of the $\mathrm{Me}_{2} \mathrm{SiO}_{2}{ }^{2-}$ ion connecting three $\mathrm{Ba}$ atoms.
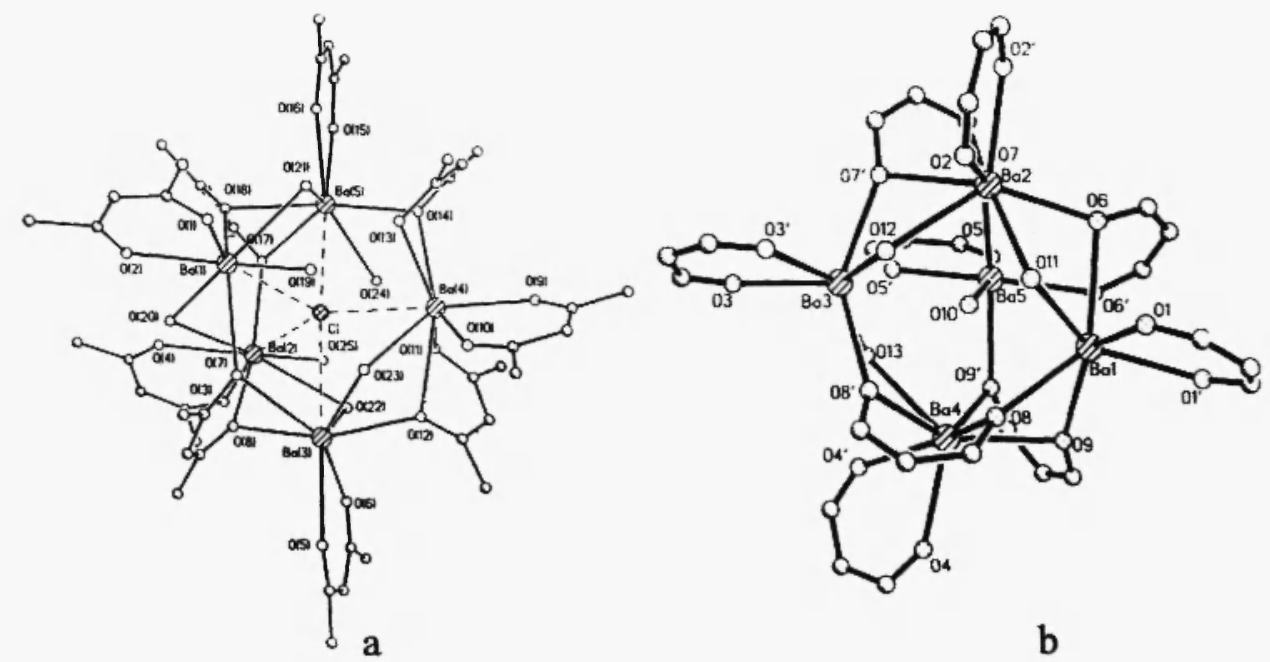

Fig. 6. Pentanuclear molecules in the crystal structure of $\mathrm{Ba}_{5}(\text { thd })_{9}(\mathrm{OH})\left(\mathrm{H}_{2} \mathrm{O}\right)_{3}(\mathrm{a})$ and $\mathrm{Ba}_{5}(\text { thd })_{9} \mathrm{Cl}\left(\mathrm{H}_{2} \mathrm{O}\right)_{7}$ (b). 


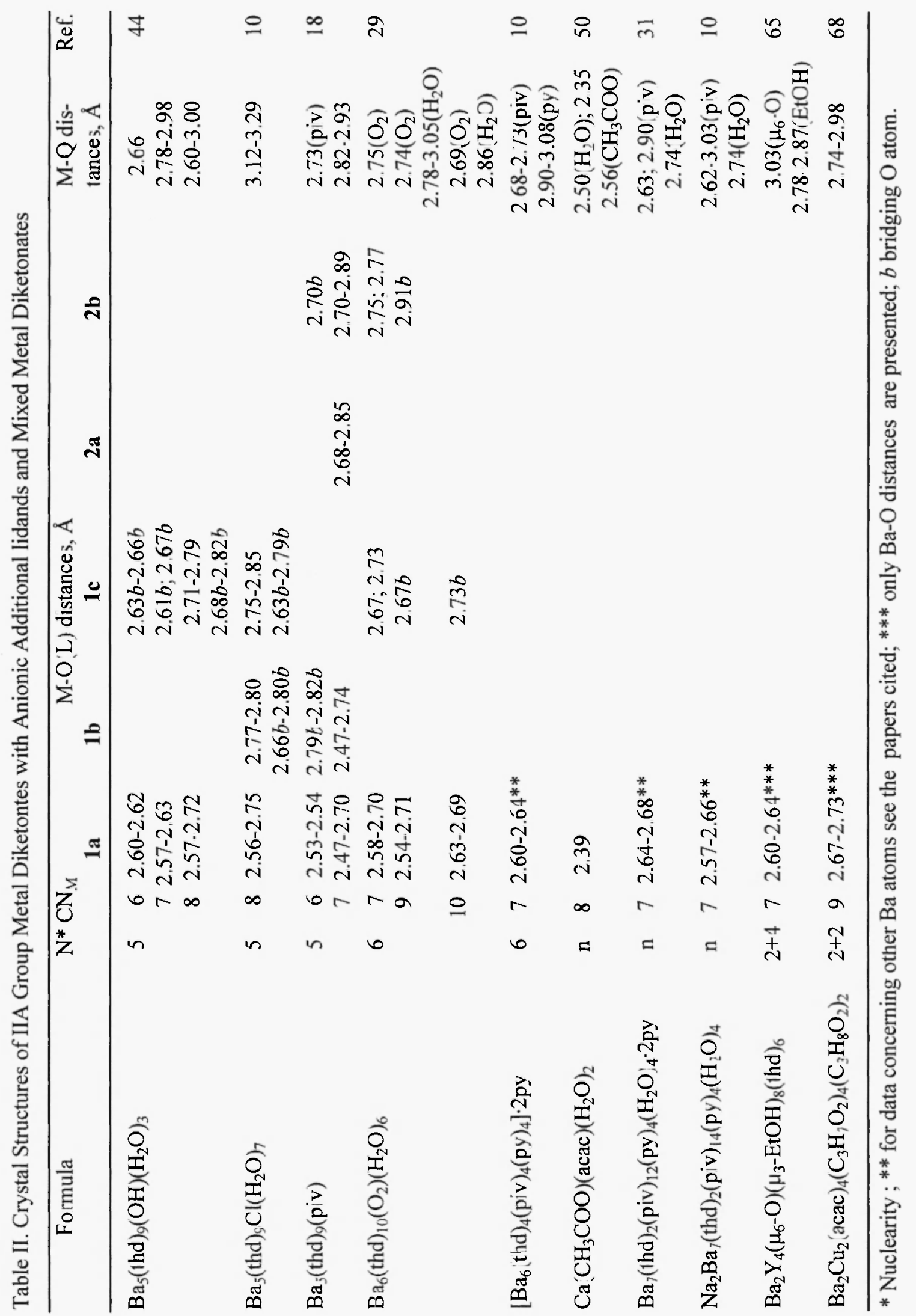




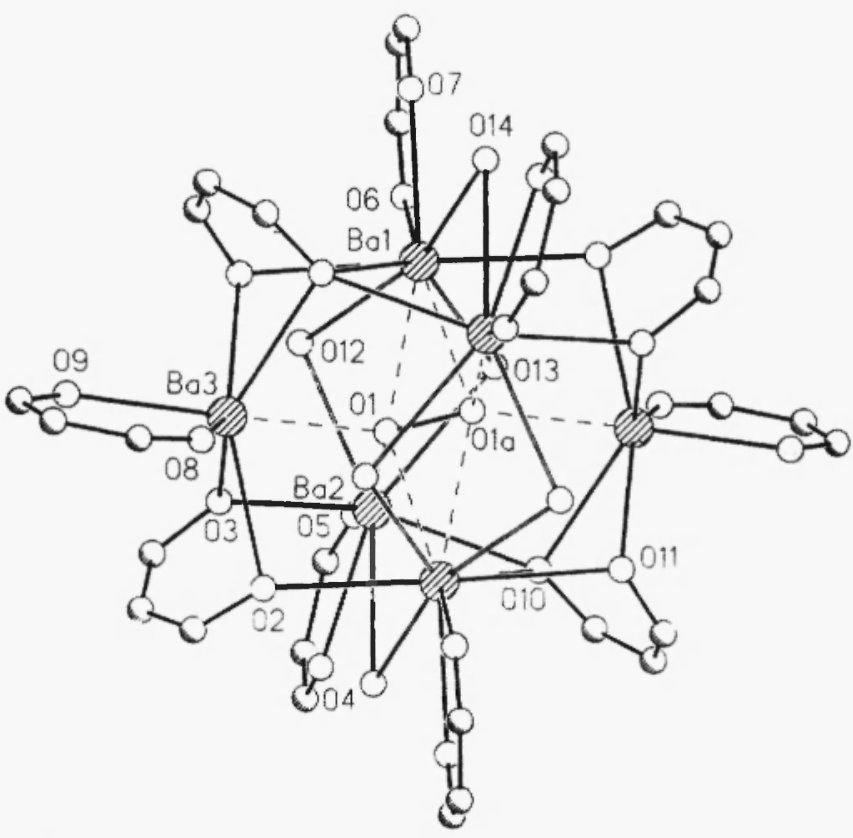

Fig. 7. Hexanuclear unit in the crystal structure of $\mathrm{Ba}_{6}(\text { thd })_{10}\left(\mathrm{O}_{2}\right)\left(\mathrm{H}_{2} \mathrm{O}\right)_{6}$.
A relationship between the size of the additional ligand and the structure of the chelate can be clearly demonstrated by the example of the peroxocomplex $\mathrm{Ba}_{6}(\text { thd })_{10}\left(\mathrm{O}_{2}\right)\left(\mathrm{H}_{2} \mathrm{O}\right)_{6}$, which was independently obtained in three different laboratories [27-29] (Fig. 7). Like the piv and siloxane ions, $\mathrm{O}_{2}{ }^{2-}$ has also two donor oxygens, but they are situated much closer to each other. This results in the formation of the hexanuclear species with $\mathrm{Ba}$ atoms situated in the apexes of a tetragonal distorted octahedron. Thd-ligands in this compound are of three types: 1a, $\mathbf{2 a}$ and $\mathbf{2 b}$, all the water molecules are bidentate bridging.

One more example of the hexanuclear complex is $\left[\mathrm{Ba}_{6}(\text { thd })_{4}(\text { piv })_{8}(\text { py })_{4}\right] \cdot 2$ py $[10]$. The metal frame consists of two $\mathrm{Ba}_{3}$ tri-

angles linked in a hexanuclear molecule by four pivalate groups. The coordination of two $\mathrm{Ba}$ atoms contains four piv-groups $\left(\mathrm{CN}_{\mathrm{Ba}}=10\right)$, while the four remaining $\mathrm{Ba}$ atoms are chelated by the 1a thd-ligands, bridging piv-ions and py molecules. The low $\mathrm{CN}_{\mathrm{Ba}}=7$ may be explained by the coordination of bulky thd-ligands. Some mixed ligand diketonates with both neutral $\left(\mathrm{H}_{2} \mathrm{O}\right.$, py) and anionic (carboxylate) additional ligands adopt a polymeric structure: $\left.\left[\mathrm{Ba}_{7}(\text { thd })_{2} \text { (piv) }\right)_{12}(\text { py })_{4}\left(\mathrm{H}_{2} \mathrm{O}\right)_{4}\right] \cdot 2$ py (Fig. 8) [31], $\mathrm{Na}_{2} \mathrm{Ba}_{7}(\text { thd })_{2}(\text { piv })_{14}(\text { py })_{4}\left(\mathrm{H}_{2} \mathrm{O}\right)_{4}[10]$ and

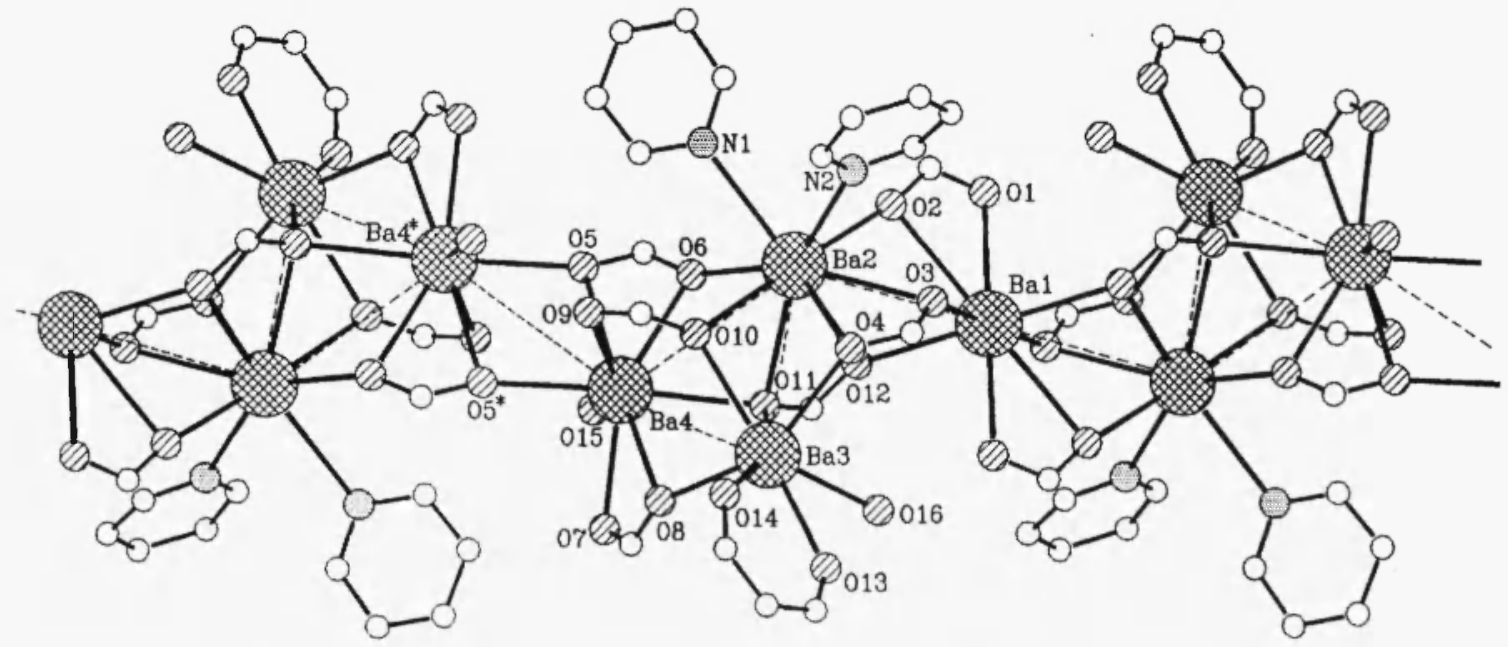

Fig. 8. The crystal structure of $\left[\mathrm{Ba}_{7}(\text { thd })_{2}(\text { piv })_{12}(\mathrm{py})_{4}\left(\mathrm{H}_{2} \mathrm{O}\right)_{4}\right] \cdot 2 \mathrm{py}$. Infinite chain formed by $\mathrm{Ba}$ atoms and $\mathrm{Ba}_{3}$ triangles.

* Actually three crystal structures determined are somewhat different due to the incorporation of solvent molecules. 
$\mathrm{Ca}(\mathrm{CH} 3 \mathrm{COO})(\mathrm{acac})\left(\mathrm{H}_{2} \mathrm{O}\right)_{2}$ [50]. In these compounds the metal atoms are linked into the polymer by the carboxylate groups while diketonates of type 1a are not bridging. In two $\mathrm{Ba}$ complexes there are alternating $\mathrm{Ba}$ triangles and separate $\mathrm{Ba}$ atoms being linked by the bridging $\mathrm{O}$ atoms from the pivalate or via bridging piv groups (in the latter case every $\mathrm{O}$ atom in piv is monodentate) (Fig. 8). In the mixed ligand calcium acetato-acetylacetate the metal atoms are bound to the infinite chain by chelating bridging aceto-groups.

\subsubsection{Neutral Lewis bases}

We are coming now to the crystal structures of the mixed ligand complexes with general formula $M_{n} L_{2 n} Q_{m}$, where $M$ is IIa group metal (except Be), HL, a diketone and $Q$, a neutral O- or $\mathrm{N}$-donor Lewis base. As in the majority of these compounds the ligand $\mathrm{Q}$ is not firmly bound to the metal atom (if compared to M-L bonds) and readily eliminates while heating, this group of mixed ligand complexes is usually referred to as adducts. The compounds of this type are dinuclear or mononuclear chelates with the CN's from 8 to 9 if $\mathrm{M}=\mathrm{Sr}, \mathrm{Ba}$, from 6 to 8 in the case of $\mathrm{Ca}$ and 6 for magnesium. At first we will discuss the dinuclear compounds (Table III).

All the dinuclear adducts known can be divided into three different groups in accordance with linking type of two mononuclear fragments into a dimeric species. The linkage occurs by:

- two diketonates with coordination mode 2a (type A);

- the diketonates of mode $1 \mathbf{b}$ (type B);

- one or some additional ligands (type $\mathrm{C}$ ).

Until now, the adducts of the type $\mathrm{A}$ are known for barium complexes with nonfluorinated diketones only, the $\mathrm{CN}$ of $\mathrm{Ba}$ being seven or eight. The first chelate of this group published was the adduct $\mathrm{Ba}_{2}(\text { thd })_{4}\left(\mathrm{NH}_{3}\right)_{4}[47,51]$. The $\mathrm{Ba}$ atoms in this dimeric molecule are linked by two double chelating (mode 2a) thd ligands. Two other thd ligands form six-member chelate rings with $\mathrm{Ba}$ atoms (type 1a). The coordinated $\mathrm{NH}_{3}$ molecules complete the $\mathrm{CN}$ of $\mathrm{Ba}$ to 8 . A very similar structure is found for $\mathrm{Ba}_{2}$ (thd) $)_{4}$ (dipy) $)_{2}$ [31] (Fig. 9), in which four positions of four $\mathrm{NH}_{3}$ ligands are replaced by two dipy molecules. In the compound $\mathrm{Ba}_{2}(\mathrm{thd})_{4}\left(\mathrm{Et}_{2} \mathrm{O}\right)_{2}$ [11] there are only two monodentate additional ligands, therefore the $\mathrm{CN}$ of $\mathrm{Ba}$ is 7 .

To the type $\mathrm{B}$ of the dinuclear adducts belong the compounds wherein the metal atoms are linked in a dimeric molecule by two or four ligands with the coordination mode $\mathbf{1 b}$. Thus, in

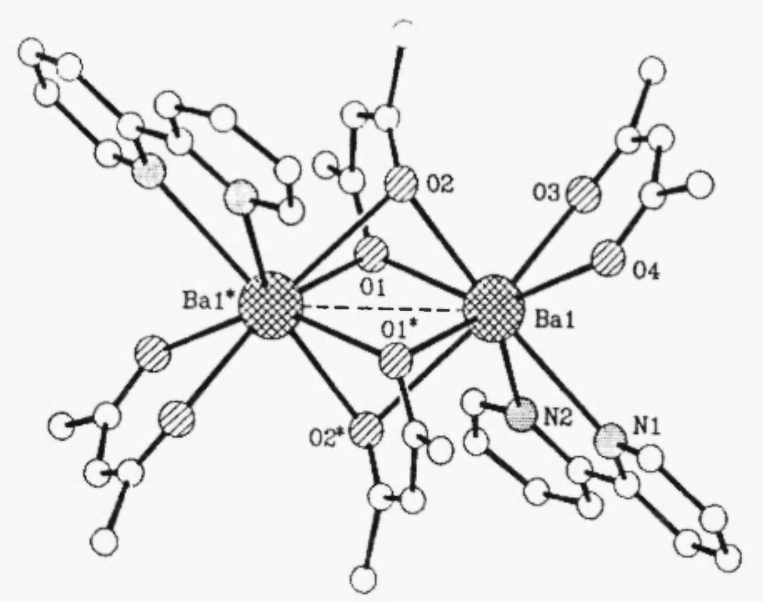

Fig. 9. Dimer in the crystal structure of $\mathrm{Ba}_{2}$ (thd $)_{4}(\text { dipy })_{2}$.
$\mathrm{Ca}_{2}(\mathrm{hfa})_{4}\left(\mathrm{H}_{2} \mathrm{O}\right)_{4}$ [41] every $\mathrm{Ca}$ atom is coordinated with one $1 \mathrm{a}$, one $1 \mathrm{~b}$ hfaligands and with two water molecules. As in the hydrated barium hexafluoroacetylacatonate discussed above (section 2.2.1.) the $\mathrm{Ca}$...F interactions increase the $\mathrm{CN}(\mathrm{Ca})$ to eight.

$\mathrm{Sr}_{2}(\mathrm{hfhd})_{2}\left(\mathrm{H}_{2} \mathrm{O}\right)_{4}[52]$ has a similar structure (Fig. 10a), Sr...F interactions taking place also. In the compound $\mathrm{Ba}_{2}(\text { thd })_{4}(\mathrm{HOAr})_{4}(\mathrm{THF})_{2}$ [53] both $\mathrm{Ba}$ atoms are octacoordinated due to the coordination of both phenol and THF molecules. A special feature of this structure is the formation of Ar$\mathrm{OH}$...O(thd) hydrogen bonds. 


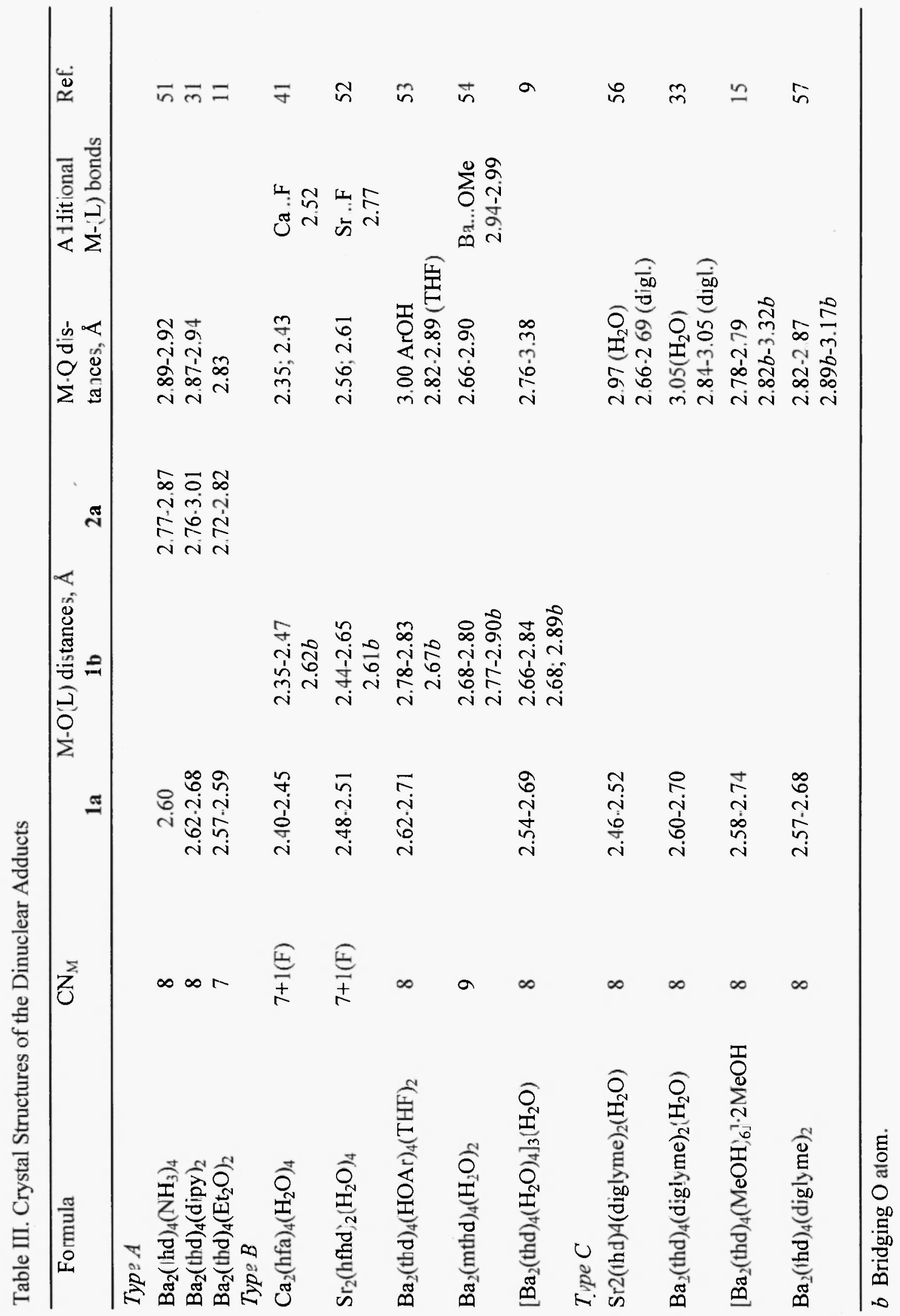



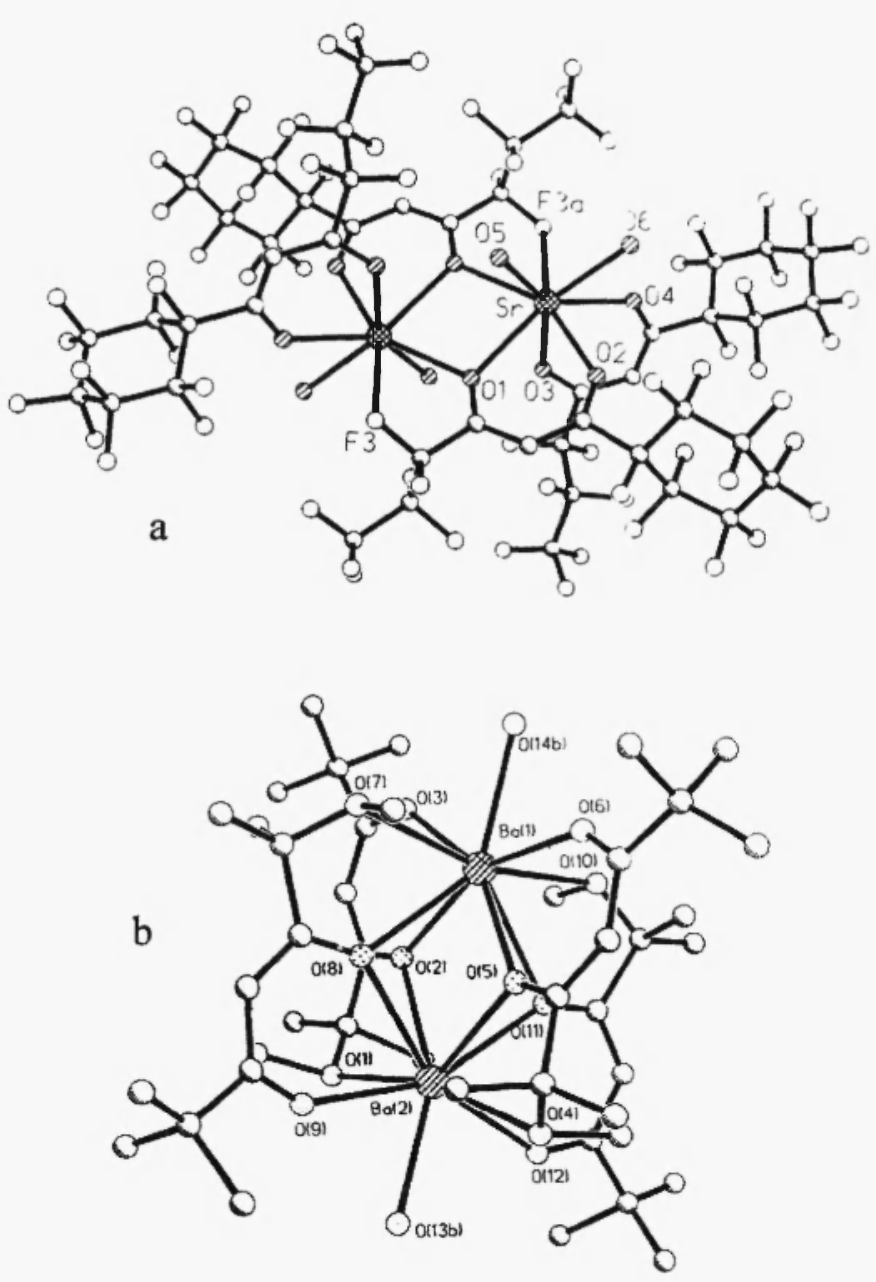

Fig. 10. Dimers in the crystal structure of $\mathrm{Sr}_{2}(\mathrm{fhd})_{4}\left(\mathrm{H}_{2} \mathrm{O}\right)_{2}$ (a) and $\mathrm{Ba}_{2}$ (mthd $)_{4}\left(\mathrm{H}_{2} \mathrm{O}\right)_{2}$ (b).

ligands belong to group $\mathrm{C}$, the diketonate ligands are of type la only, so they do not participate in linking of two mononuclear fragments into a dimer. Thus, in the isotypical compounds, $\mathrm{M}_{2}(\text { thd })_{4}(\text { diglyme })_{2}\left(\mathrm{H}_{2} \mathrm{O}\right)$, where $\mathrm{M}=\mathrm{Sr}$ [56], $\mathrm{Ba}$ [33] (Fig. 1 la) $\mathrm{M}$ (thd) ${ }_{2}$ (diglyme) fragments are linked with each other by a bridging water molecule $(\mathrm{O}(8))$. Diglyme forms three $\mathrm{M}-\mathrm{O}$ bonds with the metal atom.

The compound $\left.\left[\mathrm{Ba}_{2} \text { (thd }\right)_{4}(\mathrm{MeOH})_{6}\right] \cdot 2 \mathrm{MeOH}[15]$ is an example of the dimeric chelate with two bridging additional ligands. A dimeric molecule consists of two $\mathrm{Ba}(\text { thd })_{2}(\mathrm{MeOH})_{3}$ units related by a symmetry center. As in the diglyme adducts described above, every Ba atom is coordinated by two thd ligands (type 1a) and three $\mathrm{MeOH}$ molecules. If compared with $\mathrm{M}_{2}$ (thd) $)_{4}$ (diglyme) $)_{2}\left(\mathrm{H}_{2} \mathrm{O}\right) \quad[33,56], \mu-\mathrm{MeOH}$ bridges in the methanol adduct are more asymmetrical.

Of particular interest is the crystal structure of the anhydrous adduct $\mathrm{Ba}_{2}(\text { thd })_{4}(\text { diglyme })_{2}$ [57] (Fig. I1b) that also consists of dimeric molecules. Every Ba atom is coordinated by eight oxygen atoms, coming from two thd ligands with (mode la, $4 \mathrm{O}$ atoms), of the own diglyme molecule $(3 \mathrm{O}$ ) and of the neighboring diglyme molecule $(1 \mathrm{O})$ which chelates another $\mathrm{Ba}$ atom in this dimer. The coordination polyhedron can be interpreted as a distorted square antiprism. Opposite to the hydrated complex two $\mathrm{Ba}$ atoms are linked in a dimer due to the additional 

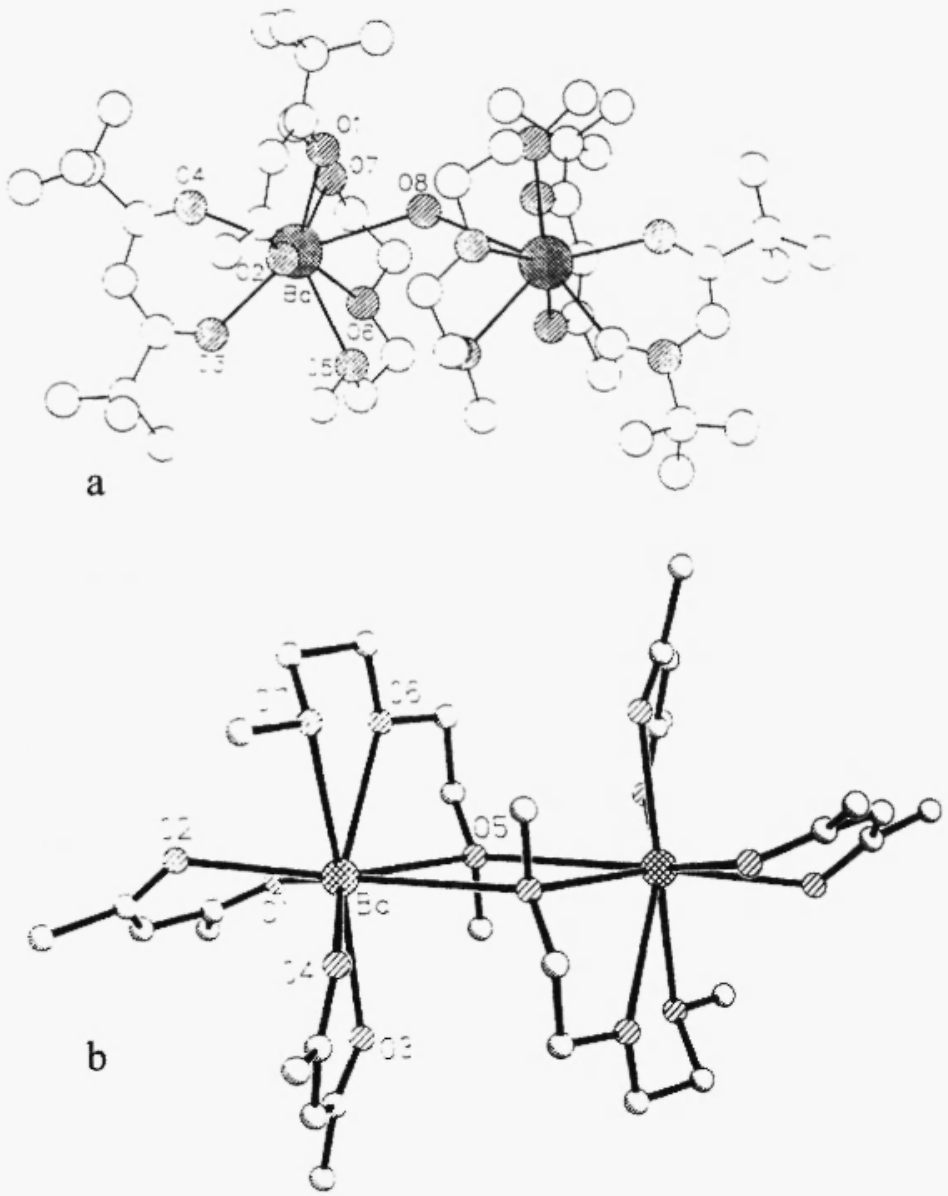

Fig. 11. Different dimers of type $\mathrm{C}$ in the crystal structure of $\mathrm{Ba}_{2}$ (thd $)_{4}($ diglyme $)\left(\mathrm{H}_{2} \mathrm{O}\right)$ (a) and $\mathrm{Ba}_{2}(\text { thd })_{4}($ diglyme $)(\mathrm{b})$. interaction between one of the oxygen atoms of the diglyme molecule with the adjacent $\mathrm{Ba}$ atom $\left(\mathrm{Ba}-\mathrm{O}(5) 2.89 \AA, \mathrm{Ba}^{\prime}-\mathrm{O}(5)\right.$ $3.17 \AA$ ). The Ba-O (diglyme) distances in this complex are somewhat shorter than those in the hydrated one. The structural chemistry of mononuclear adducts with general formula $\mathrm{ML}_{2} \mathrm{Q}_{\mathrm{n}}$ is much simpler (Table IV). All the compounds of this group contain exclusively the diketonates ligands with the coordination mode 1a. Only the variation of the additional ligands contributes to some diversity in their structure. The adduct $\mathrm{Ba}_{2}$ (thd $)_{2}\left(\mathrm{H}_{2} \mathrm{O}\right)_{2}(\mathrm{MeOH})_{2}$ [16] consists of the centrosymmetrical molecules with the Ba atom located on the two-fold axis. It is coordinated by two thd-ligands, two water and two methanol molecules.

A series of adducts with tetraglyme with a formula $\mathrm{ML}_{2}$ (tetraglyme) is of current interest. Seven crystal structures have been determined (for

$\mathrm{HL}=\operatorname{Hhfa}\left[47,58,59^{*}\right]$, Hpta [60,61], Htfa [58], Hthd [33,38, 58], Htdfnd [61a] if M=Ba; $\mathrm{HL}=\mathrm{dbzm}$ if $\mathrm{M}=\mathrm{Sr}$ [38] and $\mathrm{HL}=\mathrm{Hhfa}$ if $\mathrm{M}=\mathrm{Ca}$ [36]). A great interest evolved by this group of compounds can be demonstrated by the fact that the crystal structures of $\mathrm{Ba}(\text { thd })_{2}$ (tetraglyme) and the corresponding hfa-chelate have been determined three times each. In these adducts diketonate ligands form 1a chelate rings with the central atom, the tetraglyme molecule surrounds the metal atom being coordinated by all the five donor oxygens if $\mathrm{M}=\mathrm{Sr}, \mathrm{Ba}$ and by only four ones in the case of calcium [36]. In the chelates containing asymmetrical diketonate ligands such as pta [60, 61] (Fig. 12) or $\mathrm{tfa}$ [58], they are arranged in such a way that the $\mathrm{CF}_{3}$-groups are situated in cispositions with respect to the metal atom. If analyzing the $\mathrm{Ba}-\mathrm{O}(\mathrm{L})$ distances in the tetraglyme adducts one can notice that the average $\mathrm{Ba}-\mathrm{O}(\mathrm{L})$ bond length increase in a row thd $<$ tfa $<$ hfa $<$ tdfnd $<$ pta from 2.63 to $2.74 \AA$. This order could be explained by the simultaneous influence of two factors: the decrease of $\mathrm{M}-\mathrm{O}(\mathrm{L})$ interaction by the introduction of the trifluoromethyl acceptors and steric hindrance caused by the incorporation of bulky ligands.

The use of the polyethers with the number of donor atoms more than in tetraglyme allows to obtain complexes with the $\mathrm{CN}_{\mathrm{Ba}}=10$ (4 oxygen atoms from two diketonate ligands and 6 oxygen

* The adduct $\mathrm{Ba}(\mathrm{hfa})_{2}(8$-azatetraglyme) adopts virtually the same molecular structure [75]. 
Table IV. Crystal Structures of the Mononuclear Adducts and Anionic Diketonates

\begin{tabular}{|c|c|c|c|c|}
\hline Formula & $\mathrm{CN}_{\mathrm{M}}$ & $\begin{array}{c}\mathrm{M}-\mathrm{O}(\mathrm{L}) \\
\text { distances, } \AA\end{array}$ & $\begin{array}{c}\mathrm{M}-\mathrm{Q} \\
\text { distances, } \AA\end{array}$ & Ref. \\
\hline $\mathrm{Ba}(\text { thd })_{2}\left(\mathrm{H}_{2} \mathrm{O}\right)_{2}(\mathrm{MeOH})_{2}$ & 8 & $2.73-2.76$ & $2.72\left(\mathrm{H}_{2} \mathrm{O}\right) ; 2.78(\mathrm{MeOH})$ & 16 \\
\hline $\mathrm{Ba}(\mathrm{hfa})_{2}$ (tetraglyme) & 9 & $2.70-2.71$ & $2.81-2.89$ & 58,59 \\
\hline $\mathrm{Ba}(\mathrm{hfa})_{2}(8$-azatetraglyme $)$ & 9 & $2.69-2.74$ & $2.83-2.85(\mathrm{O}) ; 2.88(\mathrm{~N})$ & 75 \\
\hline $\mathrm{Ba}(\text { pta })_{2}$ (tetraglyme) & 9 & $2.68-2.74$ & $2.87-2.90$ & 60 \\
\hline $\mathrm{Ba}(\mathrm{tfa})_{2}$ (tetraglyme) & 9 & $2.66-2.72$ & $2.85-2.87$ & 58 \\
\hline $\mathrm{Ba}(\text { thd })_{2}$ (tetraglyme) & 9 & $2.63-2.71$ & $2.85-2.97$ & 33,58 \\
\hline $\mathrm{Ba}(\text { tdfnd })_{2}$ (tetraglyme) & 9 & $2.69-2.74$ & $2.85-2.87$ & $61 \mathrm{a}$ \\
\hline $\mathrm{Ba}(\mathrm{hfa})_{2}$ (mbhexaglyme) & 10 & $2.71-2.81$ & $2.81-2.88$ & $61 b$ \\
\hline $\mathrm{Ca}(\mathrm{hfa})_{2}$ (tetraglyme) & 8 & $2.39-2.41$ & $2.43-2.50$ & 36 \\
\hline $\operatorname{Sr}(\mathrm{dbzm})_{2}$ (tetraglyme) & 9 & $2.50-2.56$ & $2.71-2.79$ & 58 \\
\hline $\mathrm{Ca}(\text { thd })_{2}$ (triglyme) & 8 & $2.35-2.38$ & $2.47-2.59$ & 36 \\
\hline $\mathrm{Sr}(\text { thd })_{2}($ triglyme $)$ & 8 & $2.47-2.52$ & $2.63-2.71$ & 56 \\
\hline $\mathrm{Ba}(\text { thd })_{2}$ (triglyme) & 8 & $2.62-2.64$ & $2.81-2.90$ & 36 \\
\hline $\mathrm{Ba}(\mathrm{tfa})_{2}$ (hmteta) & 8 & $2.67-2.69$ & $2.96-3.02$ & 62 \\
\hline $\mathrm{Ba}(\mathrm{hfa})_{2}(18-\mathrm{C}-6)$ & 10 & $2.70-2.80$ & $2.79-3.02$ & 26 \\
\hline $\mathrm{Ba}(\mathrm{hfa})_{2}(18-\mathrm{C}-6)$ & 10 & 2.81 & $2.70-3.10$ & 25 \\
\hline \multirow[t]{2}{*}{$\mathrm{Ba}(\mathrm{hfa})_{2}(\mathrm{aza}-18-\mathrm{C}-6)^{\mathrm{a}}$} & 10 & $2.81-2.87$ & $2.79-2.84$ & 75 \\
\hline & $10^{\mathrm{b}}$ & $2.82 ; 2.93$ & $2.76-2.86$ & \\
\hline $\mathrm{Ba}(\mathrm{hfa})_{2}(\text { diaza- } 18-\mathrm{C}-6)^{\mathrm{c}}$ & 10 & 2.75 & $2.91 ; 3.00(\mathrm{O}) ; 2.96(\mathrm{~N})$ & 76 \\
\hline $\operatorname{Mg}(\text { thd })_{2}$ (phen) & 6 & $2.01-2.04$ & $2.18-2.22$ & 63 \\
\hline $\mathrm{Ca}(\text { thd })_{2}(\text { phen })_{2}$ & 8 & $2.36-2.38$ & $2.59-2.67$ & 32 \\
\hline $\operatorname{Sr}(\text { thd })_{2}$ (phen $)_{2}$ & 8 & $2.46-2.57$ & $2.71-2.83$ & 32 \\
\hline $\mathrm{Ba}(\text { thd })_{2}(\text { phen })_{2}$ & 8 & $2.61-2.73$ & $2.90-2.99$ & 35 \\
\hline $\mathrm{Mg}(\mathrm{acac})_{2}\left(\mathrm{H}_{2} \mathrm{O}\right)_{2}$ & 6 & $2.03-2.04$ & 2.15 & 5 \\
\hline $\mathrm{Mg}(\mathrm{dbzm})_{2}(\mathrm{DMF})_{2}$ & 6 & $2.06-2.07$ & 2.10 & 6 \\
\hline $\mathrm{Ca}(\mathrm{acac})_{2}\left(\mathrm{H}_{2} \mathrm{O}\right)_{2}$ & 6 & $2.32-2.34$ & 2.36 & 64 \\
\hline$[\mathrm{tmhd}]\left[\mathrm{Mg}(\mathrm{hfa})_{3}\right]$ & 6 & $2.04-2.09$ & & 65 \\
\hline$\left[\mathrm{enH}_{2}\right]_{15}\left[\mathrm{Ba}(\mathrm{hfa})_{5}\right] \mathrm{EtOH}$ & $9+1$ & $2.73-2.86^{\mathrm{d}}$ & & 44 \\
\hline
\end{tabular}

a 1-aza-4,7,10,13,16-pentaoxacycloocta-decane; ${ }^{b}$ the second crystallographically independent molecule (five $\mathrm{O}$ atoms and $\mathrm{NH}$-group found to be disordered); ${ }^{\mathrm{c}} 1,10$-diaza-4,7,13,16tetraoxacyclooctadecane; ${ }^{d}$ For monodentate hfa Ba-O 2.80 $\AA$, Ba...F 3.29 $\AA$.

atoms from polyether molecule), as in $\mathrm{Ba}(\mathrm{hfa})_{2}$ (mbhexaglyme) [61b] (one O-atom of the polyether is not coordinated to the metal).

Triglyme adducts are also mononuclear. To our knowledge, only three crystal structures have been studied, all containing thd: $\mathrm{M}(\text { thd })_{2}$ (triglyme), $\mathrm{M}=\mathrm{Ca}$ [36], $\mathrm{Sr}$ [56], $\mathrm{Ba}$ [36]. In all of 


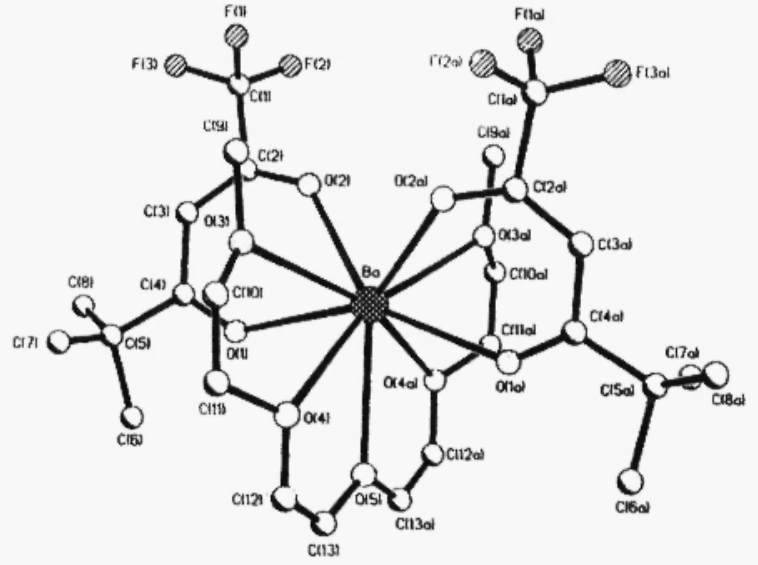

Fig. 12. Mononuclear complex in the crystal structure of $\mathrm{Ba}(\mathrm{pta})_{2}$ (tetraglyme). them triglyme molecule is tetradentate. So, the $\mathrm{CN}$ of the metal is eight. $\mathrm{CN}=8$ for $\mathrm{Ca}$ appears to be the highest possible since in the adduct with tetraglyme (which contains one donor oxygen more than triglyme) the terminal methoxy group is not bound with the central atom. The $\mathrm{N}$-donor Lewis bases that are structurally similar to the polyethers (glymes) are polyamines, therefore it is not surprising that the structure of $\mathrm{Ba}(\mathrm{hfa})_{2}$ (hmteta) [62] is similar to that of $\mathrm{Ba}(\mathrm{hfa})_{2}$ (tetraglyme).

The adduct with the crown-ether $\mathrm{Ba}(\mathrm{hfa})_{2}(18-\mathrm{C}-6)$ is known in two crystal modifications: one (modification $a$ ) obtained from the vapor [26], another (modification $b$ ) - from solution [25]. Modifica-

tion $a$ consists of molecules with the central atom coordinated by two 1a-chelating hfa ligands situated on one side and by the hexadentate crown-ether molecule on the other. In modification $b$ two hfa-ligands are located on the different sides from the plane of the crown-ether. Two hfa chelate rings are twisted in such a way that the angle between them is $85.2^{\circ}$. While in modification $b \mathrm{Ba}$ atom occupies the centre of the of $18-\mathrm{C}-6$, in modification $a$ it is spaced $1.41 \AA$ apart from the middle plane of the crown ether*. Therefore, it is surprising that both have the same volume per molecule. The Ba-O distances presented in the Table IV demonstrate nearly the same bond strength with both types of ligands. In the modification $b$ the average $\mathrm{Ba}-\mathrm{O}(\mathrm{hfa})$ distance is $2.82 \AA$, that is $0.08 \AA$ longer than in that in $a$. The comparison of $\mathrm{Ba}-\mathrm{O}$ (crown) distances is not possible due to some disorder of the crown ligand in the structure $b$.

The 1,10-phenanthroline adducts are known for $\mathrm{HL}=\mathrm{Hthd}$ and for all IIA group metals discussed. If $\mathrm{M}$ is an alkaline-earth metal $(\mathrm{M}=\mathrm{Ca}$ [32], $\mathrm{Sr}$ [32], $\mathrm{Ba}$ [35]) the compound has a general formula $\mathrm{M}$ (thd $)_{2}$ (phen) $)_{2}$; the molecule contains two trans-situated 1a thd ligands. Two chelating phen molecules complete the coordination sphere of the metal to $\mathrm{CN}=8$ (Fig. 13a).

In all magnesium diketonates studied the $\mathrm{CN}$ of metal is 6 . Even while using an excess of the additional ligand (phen) the product isolated is $\mathrm{Mg}(\mathrm{thd})_{2}$ (phen) [62] (Fig. 13b), but not a diphenanthroline adduct like for $\mathrm{M}=\mathrm{Ca}, \mathrm{Sr}, \mathrm{Ba}$. In the structure of $\mathrm{Mg}(\mathrm{acac})_{2}\left(\mathrm{H}_{2} \mathrm{O}\right)_{2}$ [5] the Oatoms of the chelating acac-ions occupy the equatorial positions, while the water molecules are situated in the axial ones. A similar structure are adopted by $\operatorname{Mg}(\mathrm{dbzm})_{2}(\mathrm{DMF})_{2}$ [6] and $\mathrm{Ca}(\mathrm{acac})_{2}\left(\mathrm{H}_{2} \mathrm{O}\right)_{2}[64]$.

The structures discussed in this paragraph show that all the IIA group metal diketonates synthesized with an excess of neutral Lewis bases consist of either mononuclear or dinuclear molecules. In rare instances of the fluorinated diketonates polymeric complexes with weak Lewis bases are obtained (vide supra).

\subsection{MIXED METAL COMPLEXES}

One of the interesting ideas dealing with MOCVD of $\mathrm{YBa}_{2} \mathrm{Cu}_{3} \mathrm{O}_{7-\delta} \mathrm{HTSC}$ films is to combine yttrium, barium and copper precursors into one, in other words to obtain a mixed $\mathrm{Y}-\mathrm{Ba}-\mathrm{Cu}$ complex. Some progress has been achieved already. It concerns mixed two-metal Y-Ba and Ba-

\footnotetext{
* Similar arrangement of two hfa ligands and diaza-18-crown-6 has been found in [76].
} 

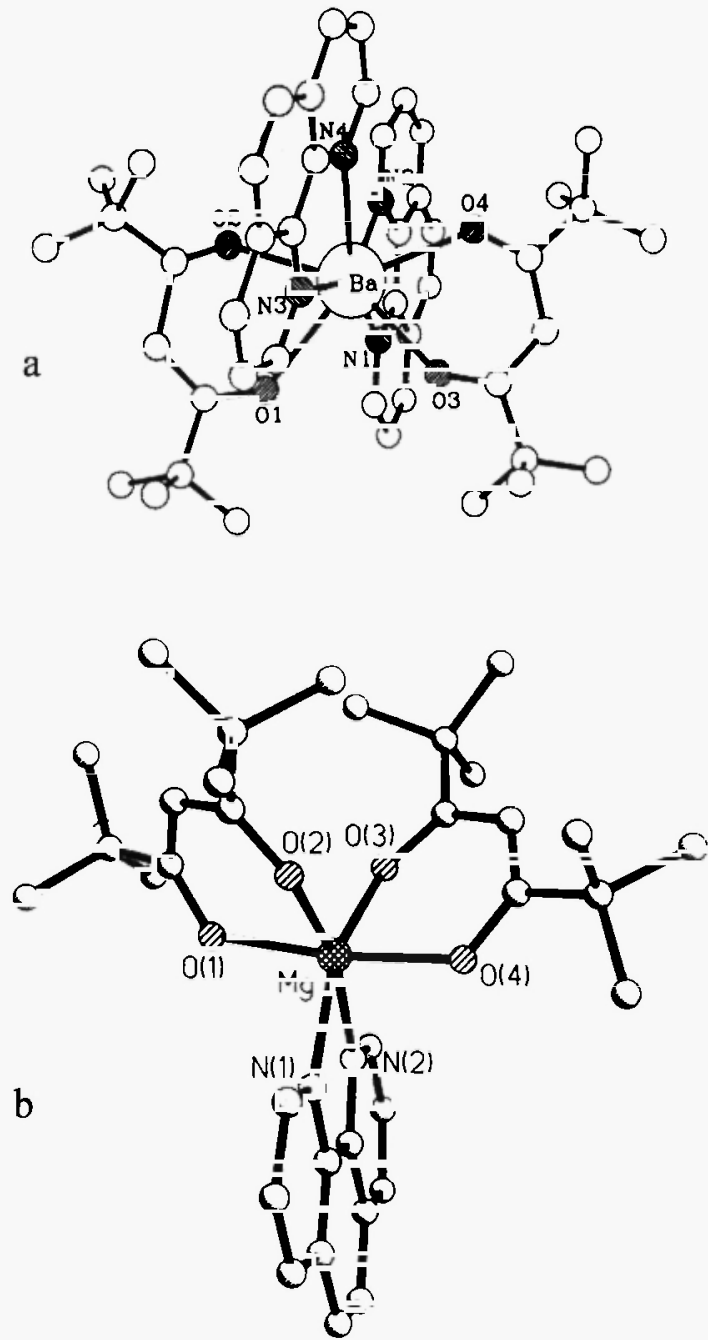

Fig. 13. Mononuclear complexes in the crystal structure of $\mathrm{Ba}$ (thd $)_{2}$ (phen $)_{2}$ (a) and $\mathrm{Mg}$ (thd $)_{2}$ (phen) (b).
Cu diketonates (Table II).

Three X-Ray structures of the mixed Y-Ba complexes are known, but only in $\mathrm{Ba}_{2} \mathrm{Y}_{4}\left(\mu_{6}-\mathrm{O}\right)\left(\mu_{3}-\mathrm{EtOH}\right)_{8}(\text { thd })_{6}[65]$ there is a diketonate coordinated to $\mathrm{Ba}$. The metal atoms in this complex are linked in an octahedron by the bridging ethoxy groups and by their $\mu_{6}-\mathrm{O}$ atom, located in the centre of this species (M- $\left(\mu_{6}-\mathrm{O}\right)$ 2.36-3.03 $\AA)$. It is one more example to show the role of small anionic ligands in the formation of the polynuclear complexes. Every metal atom in the structure is chelated by thd ligand of the type $1 \mathrm{a}$.

Two other mixed Y-Ba complexes studied $\mathrm{BaY}_{2}(\text { thd })_{4}\left(\mu_{2}-\mathrm{i}-\mathrm{C}_{3} \mathrm{HF}_{6} \mathrm{O}\right)$ [66] and $\mathrm{BaY}_{2}$ (thd $)_{4}\left(\mu_{2}-\mathrm{Si}_{2} \mathrm{O}\left(\mathrm{CH}_{3}\right)_{4} \mathrm{O}_{2}\right)$

$\left(\mu_{3} \mathrm{Si}_{3} \mathrm{O}_{2}\left(\mathrm{CH}_{3}\right)_{6} \mathrm{O}_{3}\right)(\mathrm{py})_{3}$ [67] do not contain diketonate ligands coordinated to barium. In the structure of $\mathrm{Ba}_{2} \mathrm{Cu}_{2}(\mathrm{acac})_{4}\left(\mathrm{OCH}_{2} \mathrm{CH}_{2} \mathrm{OCH}_{3}\right)_{4}\left(\mathrm{HOCH}_{2^{-}}\right.$ $\mathrm{CH}_{2} \mathrm{OCH}_{3}$ ) [68] every $\mathrm{Ba}$ atom is ninecoordinated by one acac-ion, two methoxyethylates-ions and one neutral 2-methoxyethanol molecule. It is notable that the $\mathrm{CH}_{3} \mathrm{OCH}_{2} \mathrm{CH}_{2} \mathrm{O}^{-}$ion is tetradentate (the terminal oxygen atom is tridentate), while neutral 2-methoxyethanol forms only one $\mathrm{Ba}-\mathrm{O}$ bond. The acac-ion is of type 1a like in the mixed diketonate-carboxylates. The copper atoms are in square environment which consists of the 1a acac-ion, and two O-atoms of two methoxyethylate-ions.

In the mixed dipivaloylmethanate-2-methoxyethylate $\left[\mathrm{BaCu}_{4}(\text { thd })_{4}\left(\mathrm{OCH}_{2} \mathrm{CH}_{2} \mathrm{OCH}_{3}\right)_{6}\right.$ ] [69] the $\mathrm{Ba}$ atom is located in the centre of the molecule and is bound to the 2-methoxyethylate-ions only. All four thd ligands are bound with the copper atoms. A variation in $\mathrm{Ba}-\mathrm{Cu}$ stoichiometry in these two complexes is due to the different $\mathrm{Ba}: \mathrm{Y}$ ratios of the reagents.

\subsection{ANIONIC METAL DIKETONATES}

Some examples of anionic metal diketonates are given in Table IV. In [tmndH] ${ }^{+}\left[\mathrm{Mg}(\mathrm{hfa})_{3}\right]^{-}$ [70] the central atom is chelated by three hfa ions (mode 1a) which form three planar six-member chelate rings. Apparently, calcium is able to coordinate four bidentate hfa-ligands as in the compound $[\mathrm{tmndH}]_{2}^{+}\left[\mathrm{Ca}(\mathrm{hfa})_{4}\right]^{2-}[71]$, but there are no structural data available. In the case of $\mathrm{Ba}$ even a pentakis anionic complex $\left[\mathrm{enH}_{2}\right]_{1.5}\left[\mathrm{Ba}(\mathrm{hfa})_{5}\right] \mathrm{EtOH}$ [44] has been isolated. It consists of ethylenediammonium cations solvated by 3 -ethanol and anions $\left[\mathrm{Ba}(\mathrm{hfa})_{5}\right]^{3-}$ linked to one another by $\mathrm{H}$-bonds of types (en) $\mathrm{H} \ldots \mathrm{O}(\mathrm{hfa})$ and $(\mathrm{en}) \mathrm{H} \ldots \mathrm{O}(\mathrm{EtOH})$. The $\mathrm{Ba}$ atom is coordinated by nine $\mathrm{O}-$ atoms from five hfa-anions. Four of them chelate $\mathrm{Ba}$ (mode 1a), while the fifth ligand is 
monodentate. As we know Ba complexes with $\mathrm{CN}$ higher than in this one, the absence of the tenth $\mathrm{Ba}-\mathrm{O}$ interaction could be explained by steric hindrance.

\subsection{SOME CORRELATIONS IN THE STRUCTURAL CHEMISTRY}

The analysis of the crystal structures discussed makes possible to find some tendencies in the $\mathrm{M}-\mathrm{O}(\mathrm{L})$ distance dependence on the $\mathrm{CN}$ of the metal atom, i.e. on the number of $\mathrm{M}-\mathrm{O}(\mathrm{L})$ bonds formed. As could be expected the rise of the $\mathrm{CN}$ of $\mathrm{M}$ leads to the increase of $\mathrm{M}-\mathrm{O}$ distance. For example, in $\mathrm{Ba}_{2}(\text { thd })_{4}\left(\mathrm{Et}_{2} \mathrm{O}\right)_{2}[11](\mathrm{CN}(\mathrm{Ba})$ is seven) the average $\mathrm{Ba}-\mathrm{O}$ (thd-1a) distance is 2.58 $\AA$, while in $\mathrm{Ba}_{2}$ (thd $)_{4}$ (dipy) $)_{2}[31]\left(\mathrm{CN}_{\mathrm{Ba}}\right.$ is eight) it is somewhat longer $(2.64 \AA)$. If the $\mathrm{CN}$ of metal is fixed, the length of $\mathrm{M}-\mathrm{O}(\mathrm{L})$ bond rises from the monodentate oxygens to the bidentate ones. For instance, in $\mathrm{Ba}_{2}$ (thd $)_{4}\left(\mathrm{NH}_{3}\right)_{4}$ [51] the $\mathrm{Ba}-\mathrm{O}$ distances in the case of the monodentate $\mathrm{O}$-atoms (ligand of 1a type) are $2.60 \AA$ compared to 2.77 and $2.78 \AA$ in bidentate (2a thd) ones. The CN dependence of the $\mathrm{M}-\mathrm{O}(\mathrm{L})$ length should be more noticeable in the case of 1a-coordinated diketonates, but the high ionicity of $\mathrm{M}-\mathrm{O}(\mathrm{L})$ bond in some cases diminishes it strongly. The additional interactions between $\mathrm{O}$-atoms of the ligand and the coordinated solvent molecules as well as some $\mathrm{M} . . \mathrm{F}(\mathrm{L})$ contacts result in some increase of $\mathrm{M}-\mathrm{O}(\mathrm{L})$ bond length and therefore make the situation much more complicated.

The $\mathrm{Ba}$...Ba distances in the dinuclear compounds can be divided into three separate groups according to the types of linking of the mononuclear fragments into a dimer (vide supra). In the complexes of type $\mathrm{A}$ the $\mathrm{Ba}$... Ba distances range from 3.79 to $3.91 \AA$. In the dimers which belong to the type $\mathrm{B}$ the $\mathrm{Ba}$...Ba distances are longer. For instance, in the dinuclear fragments in $\mathrm{Ba}_{6}(\text { thd })_{12}\left(\mathrm{H}_{2} \mathrm{O}\right)_{13} \mathrm{Ba}$... Ba distance is $4.20 \AA$ [9]. The dimeric chelates of type $\mathrm{C}$ with $\mathrm{Ba}$ atoms linked by the additional ligands only $\mathrm{Ba}$...Ba distances range from 5.13 to $5.73 \AA$, that is much longer if compared with two other types. Thus, Ba...Ba distances in dimeric molecules are determined by the type of linking of the mononuclear fragment into a dimer.

\section{STRUCTURE DEPENDING PROPERTIES}

In the molecule of $\mathrm{Ba}_{4}(\text { thd })_{8} \mathrm{Ba}$ atoms possess low CN's (6 and 7) that makes this compound air-sensitive due to the hydratation, hydrolysis and carbonate formation. On the other hand, the high volatility of this compound is due to its molecular structure and weak intermolecular contacts. $\mathrm{Ba}_{4}$ (pta) $)_{8}$ possesses similar properties, but gives $\mathrm{BaF}_{2}$ as a product of decomposition. $\mathrm{Sr}_{3}$ (thd) $)_{6}$ (Hthd) [12] while heating firstly looses the diketone molecule with following sublimation of the diketonate. On the contrary, the polymeric structure of barium complexes with hexafluoroacetylacetone appears to be responsible for the rather low volatility of $\mathrm{Ba}(\mathrm{hfa})_{2}$ (according to [44] the vaporization occurs with $15-19 \%$ sample remaining). The low thermal stability of this complex may be explained by the weakening of $\mathrm{Ba}-\mathrm{O}(\mathrm{hfa})$ bonds caused by the inductive effect of the $\mathrm{CF}_{3}$-acceptors.

A good way to protect a precursor from water and $\mathrm{CO}_{2}$ from air is to saturate the coordination sphere either by modifying a diketonate (changing thd ligand by mthd, diki, triki) or by obtaining the mixed ligand complexes with neutral Lewis donors. The former compounds sublime quantitatively in vacuo, the latter first eliminate the Lewis base followed by the vaporization of the homoligand diketonate, except that some adducts of the fluorinated diketonates with tetraglyme [72, 73] or crown-ethers [74] sublime without splitting. Thus, the adduct $\mathrm{Ba}(\mathrm{tdfnd})_{2}$ (tetraglyme) sublimes in vacuo at $160^{\circ} \mathrm{C}[72 \mathrm{~b}]$. A very important property of these compounds is their low melting point, which makes it possible to make CVD of the liquid precursor. The best results are obtained with $\mathrm{Ba}(\mathrm{hfa})_{2}$ (mbhexaglyme) (m.p. $52^{\circ} \mathrm{C}[61 \mathrm{~b}]$ ), and $\mathrm{Ba}$ (tdfnd) ${ }_{2}$ (hexaglyme) (m.p. $40^{\circ} \mathrm{C}$ [73]). The incorporation of the Lewis base molecule in the coordination sphere of metal atom also results in the rise of the $\mathrm{CN}$ of metal and therefore to the increase of storage stability. Thus, tetraglyme, phen and crown-ether adducts are air-stable in 
contrast to homoligand metal diketonates. $\mathrm{Ba}(\text { diki })_{2}$ and $\mathrm{Ba}$ (triki) $)_{2}$ with $\mathrm{CN}(\mathrm{Ba})=8$ undergo irreversible changes after 2-3 h of exposure to air [22], but not after a few minutes like $\mathrm{Ba}_{4}(\text { thd })_{8}$ [34].

The use of the mixed ligand complexes with anionic additional ligands results in some decrease of the evaporation degree as compared to $\mathrm{Ba}_{4}(\text { thd })_{8}$. Actually, this compound cannot be quantitatively sublimed due to the formation of the unvolatile residue such as $\mathrm{BaCl}_{2}$ (if the initial substance is $\mathrm{Ba}_{5}(\text { thd })_{9} \mathrm{Cl}\left(\mathrm{H}_{2} \mathrm{O}\right)_{7}[10]$ ) or $\mathrm{BaO}$ (in the case of $\left.\mathrm{Ba}_{5}(\text { thd })_{9}(\mathrm{OH})\left(\mathrm{H}_{2} \mathrm{O}\right)_{3}\right)$.

Although many efforts were made to obtain a thermally stable precursor, air and water nonsensitive and reveals significant volatility the problem has not yet been solved. A success may be reached in both directions: the use of new diketonate ligands and obtaining mixed ligand complexes.

\section{REFERENCES}

1. J.G. Bednorz and K.A. Muller, Z. Phys. B, 1986, 64, 189.

2. T. Ozawa, Thermochim. Acta, 1991, 174, 185.

3. H. Zama and Sh. Oda, Jap. Journ. Appl. Phys., 1990, 29, L1072.

4. A.D. Berry, D.K. Gaskill, R.T. Holm, E.J. Cukauskas, R. Kaplan and R.L. Henry, Appl. Phys. Lett., 1988, 52, 1743.

5. B. Morosin, Acta Cryst., 1967, 22, 315.

6. F.J. Hollander, D.H. Templeton and A. Zalkin, Acta Cryst., 1973, B29, 1289.

7. S.B. Turnipseed, R.M. Barkley and R.E. Sievers, Inorg. Chem., 1991, 30, 1164.

8. A. Gleizes, S. Sans-Lenain and D. Medus, Compt. Rend. Sci. Paris, Ser. II, 1991, 313, 761.

9. A. Drozdov, S. Troyanov, A. Pisarevsky and Yu. Struchkov, Polyhedron, 1994, 13, 2459.

10. A. Drozdov, S. Troyanov, A. Pisarevsky and Yu. Struchkov, Polyhedron, 1994, 13, 1445.

11. G. Rossetto, A. Polo, F. Benetollo, M. Porchia and P. Zanella, Polyhedron, 1992, 11, 979.

12. S.R. Drake, M.B. Hursthouse, K.M.A. Malik and D.L. Otway, J. Chem. Soc., Dalton Trans., 1993, 2883.

13. H. Sato and S. Sugawara, Inorg. Chem., 1993, 32, 1941.

14. K.G. Caulton, M.H. Chisholm, S.R. Drake and K. Folting, Inorg. Chem., 1991, 30, 1500.

15. A. Gleizes, S. Sans-Lenain, D. Medus and R. Morancho, Compt. Rend. Sci. Paris, Ser. II, $1991,312,983$.

16. A. Gleizes, S. Sans-Lenain and M. Heughebaert, Compt. Rend. Acad. Sci. Paris, Ser. II, 1992, 315, 299.

17. A. Gleizes, D. Medus and S. Sans-Lenain, Mat. Res. Soc. Symp. Proc., 1992, 271, 919.

18. A. Drozdov and S. Troyanov, Polyhedron, 1992, 11, 2877.

19. A.A. Drozdov and S.I. Troyanov, J. Chem. Soc., Chem. Commun., 1993, 1619.

20. A.P. Purdy, A.D. Berry, R.T. Holm, M. Fatemi and D.K. Gaskill, Inorg. Chem., 1989, 28, 2799.

21. 1. Wakeshima and K. Yamaoko, J. Chem. Soc. Jap., 1992, 6, 619.

22. D.S. Schulz, B.J. Hinds, C.L. Stern and T.J. Marks, Inorg. Chem., 1993, 32, 249; T.J. Marks, Pure Appl. Chem., 1995, 67, 313.

23. S.C. Thompson, D.J. Cole-Hamilton, D.D. Gilliland and M.L. Hitchman, Adv. Mater. Opt. Electr., 1992, 1, 81.

24. A. Gleizes, A. Drozdov and S. Troyanov, Koord. Khim., 1994, 20, 922.

25. J.A.T. Norman and G.P. Pez, J. Chem. Soc., Chem. Commun., 1991, 971.

26. T.M. Polyanskaya, Yu.B. Gatilov, T.N. Martynova and L.D. Nikulina, Zh. Strukt. Khim., 1992, 33, 190.

27. J. Auld, A.C. Jones, A.B. Leese, B. Cockayne, P. Wright, P. O'Brien and M. Motevalli, 
J. Mater. Chem., 1993, 3, 1203.

28. N. Hovnanian, J. Galloy and P. Miele, Polyhedron, 1995, 14, 297.

29. A. Drozdov and S. Troyanov, Polyhedron, 1996, 15, 1747.

30. E. Bouwman, J.C. Huffman, E.B. Lobkovsky, G. Christou, H.-L. Tsai and D.N. Hendrickson, Inorg. Chem., 1992, 31, 4436.

31. A. Drozdov and S. Troyanov, Polyhedron, 1993, 12, 2973.

32. I. Soboleva, S. Troyanov, N. Kuzmina, V. Ivanov, L. Martynenko and Yu. Struchkov, Koord. Khim., 1995, 21, 688.

33. A. Drozdov and S. Troyanov, Koord. Khim., 1994, 20, 171.

34. N. Kuzmina, I. Zaitseva, M. Chechernikova, L. Martynenko, A. Cherednichenko and V. Vovna, Zh. Neorg. Khim., 1991, 36, 2739.

35. N. Kuzmina, V. Ivanov, S. Troyanov and L. Martynenko, J. of CVD, 1994, 3, No. 1, July, 32.

36. S.R. Drake, S.A.S. Miller and D.J. Williams, Inorg. Chem., 1993, 32, 3227.

37. T.M. Polyanskaya and A.Virovets, Proceedings of the VIIth Meeting of Crystal Chemistry of Inorganic and Coordiation Compounds, 27-30 June, 1995, St. Peterburg, 125.

38. S.R. Drake, S.A.S. Miller, M.B. Hursthouse and K.M.A. Malik, Polyhedron, 1993, 12, 1621.

39. A. Alikhanyan, I. Malkerova, N. Kuzmina, V. Ivanov and A. Kaul, Zh. Neorg. Khim., 1994, 39, 1534.

40. A. Drozdov, S. Troyanov, N. Kuzmina, L. Martynenko, A. Alikhanyan and I. Malkerova, $J$. Phys. IV, 1993, 3, 379.

41. D.C. Bradley, M. Hasan, M.B. Hursthouse, M. Motevalli, O.F.Z. Khan, R.C. Pritchard and J.O. Williams, J. Chem. Soc., Chem. Commun., 1992, 575.

42. A. Drozdov and S. Troyanov, Polyhedron, 1995, 15, 1731.

43. A. Drozdov, S. Troyanov, A. Pisarevsky and Yu. Struchkov, J. Phys. IV, 1995, 5, C5-503.

44. R.E. Sievers, S.B. Turnipseed, L. Huang and A.F. Lagalante, Coord. Chem. Rev., 1993, 128, 285.

45a. Cambridge Structural Database, Release - April, 1995.

45b. B.J. Hinds, D.B. Studebaker, J. Chen, T.J. Marks et al, J. Phys. IV, 1995, 5, C5-391.

45c. D.S. Studebaker, D.A. Neumayer, C.L. Stern, T.J. Marks, in preparation.

46. W.S. Rees, H.A. Luten, M.W. Carris, C.A. Caballero, W. Hesse and V.L. Goedken, Mat. Res. Soc. Symp. Proc., 1993, 310, 375.

47. W.S. Rees and A.R. Barron, Materials Science Forum, 1993, 137-139, 473.

48. F.J. Hollander, D.H. Templeton and A. Zalkin, Acta Cryst., 1973, B29, 1295.

49. F.J. Hollander, D.H. Templeton and A. Zalkin, Acta Cryst., 1973, B29, 1302.

50. J.J. Sahbari and M.M. Olmstead, Acta Cryst., 1985, C41, 360.

51. W.S. Rees, M.W. Carris and W. Hesse, Inorg. Chem., 1991, 30, 4479.

52. A. Pisarevsky and M. Kurykin, private communication.

53. P. Miele, J.-D. Foulon and N. Hovnanian, Polyhedron, 1993, 12, 209.

54. N.I. Snezhko and S.A. Ivanov, unpublished data.

55. S.I.Troyanov, S.A. Moros, N.I. Pechurova and N.I. Snezhko, Koord. Khim., 1992, 18, 1207.

56. S.R. Drake, M.B. Hursthouse, K.M.A. Malik and S.A.S. Miller, J. Chem Soc., Chem.

Commun., 1993, 478.

57. S.R. Drake, M.B. Hursthouse, K.M.A. Malik and S.A.S. Miller, Inorg. Chem., 1993, 32, 4653.

58. R. Gardiner, D.W. Brown, P.S. Kirlin and A.L. Rheingold, Chem. Mater., 1991, 3, 1053.

59. P. Sluis, A.L. Spek, K. Timmer and H.A. Meinema, Acta Cryst., 1990, C46, 1741.

60. N. Kuzmina, A. Drozdov, T. Zotova, G. Kupryanova, A. Pisarevsky and Yu Struchkov, Koord. Khim., 1994, 20, 743.

61. A. Drozdov and S. Troyanov, J. Phys. $I V, 1995,5$, C5-373. 
61a. J.A.P. Nash, J.C. Barns, B.C. Richards, M.L. Hitchman et al, Adv. Mater. Opt. and Electron., $1995,5,1$.

61 b. D.A. Neumayer, D.B. Studebaker, B.J. Hinds, Ch.L. Stern and T.J. Marks, Chem. Mater., 1994, 6, 878.

62. S.R. Drake, M.B. Hursthouse, K.M.A. Malik, S.A.S. Miller and D.J. Otway, Inorg. Chem., 1993, 32, 4464.

63. I.E. Soboleva, S.I. Troyanov and N.P. Kuzmina, Koord. Khim., 1996 (in press).

64. J.J. Sahbari and M.M. Olmstead, Acta Cryst., 1983, C39, 208.

65. P. Miele, J.D. Foulon, N. Hovnanian and L. Cot, J. Chem. Soc., Chem. Commun., 1993, 29.

66. F. Labrize, L.G. Hubert-Pfalzgraf; J.-C. Daran and S. Halut, J. Chem. Soc., Chem. Commun., 1993, 1556; F. Labrize, L.G. Hubert-Pfalzgraf; J.-C. Daran, S. Halut and P. Tobaly, Polyhedron, 1996, 15, 2707.

67. J.D. Foulon, P. Miele and N. Hovnanian, Z. Kristallogr., 1994, 209, 282.

68. N.N. Sauer, E. Garcia, K.V. Salazar, R.R. Ryan and J.A. Martin, J. Amer. Chem. Soc., 1990, $112,1524$.

69. W. Bidell, V. Shklover and H. Berke, Inorg. Chem., 1992, 31, 5561.

70. M.R. Truter and B.L. Vickery, J. Chem. Soc., Dalton Trans., 1972, 395.

71. D.E. Fenton and R. Newman, J. Chem. Soc, Dalton Trans., 1974, 655.

72. K. Timmer, K.I.M.A. Mackor, H.A. Meinema, A.L. Spek and P. van de Sluis, Inorg. Chim. Acta, 1991, 190, 109.

73. S.H. Shamlian, M.L. Hitchman, St.L. Cook and B.C. Richards, J. Mater. Chem., 1994, 4, 81.

74. K. Timmer and H.A. Meinema, Inorg. Chim. Acta, 1991, 187, 99.

75. M. Motevalli, P. O'Brien and I.M. Watson, Polyhedron, 1996, 15, 1865.

76. H.D. Inerowicz, M.A. Khan, G. Atkinson and R.L. White, Acta Cryst., 1994, C50,688.

Received: February 14, 1996 - Accepted: March 1, 1996 Received in revised camera-ready format: June 28, 1996 
